\title{
Zusammenfassung und Diskussion der Ergebnisse
}

Auf dem letzten ausführlichen, retrospektiv angelegten Interview G2 mit den 20 Elternteilen (vgl. Abschnitt 6.3) basierend, verfolgte die vorliegende Studie das Ziel, die verschiedenen Formen, die das verbale Motivierungshandeln der Eltern gegenüber ihren Kindern im Kontext des unklaren Übertrittsentscheids angenommen hatte, möglichst facettenreich zu beschreiben und bezüglich der Effekte auf das lern- und leistungsbezogene Denken, Fühlen und Handeln der Kinder zu beurteilen. Im Fokus standen Interviewpassagen, in denen die Eltern eigene schulbezogene Bedeutsamkeitszuschreibungen und evaluative Feedbacks geschildert hatten (vgl. Abschnitt 6.4.1). Diese «wert- und kontrollbezogenen elterlichen Regulationen» wurden entlang des von Kuckartz (2010, S. 99-107) beschriebenen Verfahrens der «Typologischen Analyse» in mehreren Schritten in jeweils unterschiedlicher Nähe zum Originaltext mittels inhaltsanalytischen und deskriptiv-quantitativen Methoden untersucht (vgl. die Übersicht in Tabelle 6.2).

Im Folgenden werden entlang der vier Hauptfragestellungen (vgl. Abschnitt 5.8) die zentralen Ergebnisse nochmals aufgenommen und mit Blick auf die im Theorieteil dargelegten Postulate und früheren Forschungsbefunde diskutiert:

In Abschnitt 8.1 werden die Hauptbefunde der fallübergreifenden niedriginferenten Analysen zu den beiden Forschungsfragen 1 und 2, welche Gestaltungsmerkmale der 194 Bedeutsamkeitszuschreibungen und der 104 evaluativen Feedbacks in den Blick nahmen, nochmals dargelegt und kommentiert.

Elektronisches Zusatzmaterial Die elektronische Version dieses Kapitels enthält Zusatzmaterial, das berechtigten Benutzern zur Verfügung steht https://doi.org/10.1007/978-3-658-33062-0_8. 
In Abschnitt 8.2 stehen die Ergebnisse der fallspezifischen höher-inferenten Analysen zu den Fragestellungen 3 und 4 nach den individuellen Stilen des verbalen Motivierens der 18 diesbezüglich untersuchten Elternteile bzw. nach der Typologie, zu der sich die Stilmerkmale verdichten ließen, nochmals im Mittelpunkt. Ein besonderes Augenmerk gilt hierbei den im letzten Analyseschritt herausgearbeiteten vier Typen des verbal-appellativen Motivierungshandelns, welche hinsichtlich der Bedingungen ihres Auftretens, aber auch hinsichtlich der Chancen und Risiken für das motivational-affektive Erleben des Kindes sowie für sein Lern- und Leistungshandeln kommentiert werden.

In Abschnitt 8.3 werden die zur Ermittlung der Befunde eingesetzten Erhebungs- und Analysemethoden kritisch erörtert und Folgerungen für die weitere Forschung zum verbalen Motivierungshandeln von Eltern im Lern- und Leistungskontext gezogen. Zum Schluss werden in Abschnitt 8.4 Konsequenzen für die pädagogische Praxis formuliert.

\subsection{Gestaltungsmerkmale von elterlichen Wert- und Kontrollregulationen}

Wie gestalten die 20 Eltern ihre verbalen Bedeutsamkeitszuschreibungen - «messages about their own values» (Jacobs \& Eccles, 2000, S. 427) -, mit denen sie ihre Kinder von einer veränderten Sicht und einem veränderten Handeln in Bezug auf schulische Ziele zu motivieren suchen?

Wie gestalten sie ihre evaluativen Feedbacks, mit denen sie als «interpreters of reality» (Jacobs \& Eccles, 2000, S. 426) auf die Attributionsprozesse ihrer Kinder und somit auf deren Kontrollüberzeugungen mit Bezug auf schulische Ziele Einfluss nehmen?

Die beiden fallübergreifenden Fragestellungen 1 und 2 nach den Gestaltungsmerkmalen der 194 Bedeutsamkeitszuschreibungen und der 104 evaluativen Feedbacks, welche sich in der Basiscodierung (Analyseschritt A, vgl. Abschnitt 6.4.1) der 20 Interviews hatten isolieren lassen, wurden im Rahmen der «Feincodierung» (Analyseschritt B) mittels der strukturierenden qualitativen Inhaltsanalyse (vgl. Kuckartz, 2018, S. 100-117) bearbeitet (vgl. Abschnitt 6.4.2). Zwei Gruppen von Gestaltungsmerkmalen standen bei Analysen der elterlichen Bedeutsamkeitszuschreibungen und evaluativen Feedbacks im Fokus: Einerseits interessierte, welche schulischen Ziele (vgl. Kategoriensysteme in Tabelle 6.6 und Tabelle 6.8) die Elternteile in Anbetracht des unklaren Übertrittsentscheids zum Gegenstand ihrer Wert- und Kontrollregulationen gemacht hatten. Andererseits sollten die für die Motivation und das affektive Erleben der Kinder relevanten Argumentationen, 
welche die Elternteile in diesen Regulationen eingesetzt hatten, mit Hilfe der beiden Kategoriensysteme «Elterliche Strategien der verbalen Wertvermittlung» (vgl. Abbildung 5.4) und «Elterliche Strategien der verbalen Kontrollvermittlung» (vgl. Abbildung 5.3) untersucht werden.

Während die Instrumente zur Codierung der fünf Zielbereiche theorie- und datengestützt auf der Grundlage der Taxonomie von Kompetenzen nach Erpenbeck und von Rosenstiel (2003) entwickelt wurden (vgl. Abschnitt 6.4.2.1), lag den 16 kontrollbezogenen Begründungstypen, die zur Codierung der Argumentationsstrukturen der evaluativen Feedbacks der Elternteile herangezogen wurden, das Klassifikationsschema kausaler Attributionen von Weiner (1994, S. 271) zugrunde (vgl. Abschnitt 5.4.1). Das Kategoriensystem zur Codierung der acht wertbezogenen Begründungstypen wurde an den Daten der vorliegenden Wertepisoden und auf der Basis der Theorie des Subjective Task Value von Eccles, Wigfield et al. (1992, 2005) entwickelt.

Zuerst werden im Folgenden die wichtigsten Erkenntnisse der diesbezüglichen Untersuchungen, die an den Wertepisoden durchgeführt wurden, zusammengefasst und kommentiert, danach diejenigen, die aus den Analysen der Kontrollepisoden hervorgegangen sind.

\subsubsection{Fokussierte schulbezogene Ziele der elterlichen Wertregulationen}

In den 20 Interviews fand sich ein breites Spektrum an schulischen Handlungsund Leistungszielen, auf deren Bedeutung die Elternteile die Aufmerksamkeit des Kindes zu lenken suchten (vgl. Abschnitt 7.1.1). Die strukturierenden qualitativen Inhaltsanalysen, denen die 194 Wertepisoden auf der Grundlage der in Tabelle 6.5 und Tabelle 6.6 dargestellten Kategoriensysteme unterzogen wurden, offenbarten, dass die Elternteile vornehmlich von Wertregulationen berichteten, die im Rahmen von häuslichen Gesprächen über Hausaufgaben und Prüfungsvorbereitungen sowie von Gesprächen über den Übertritt erfolgt waren:

Die Hausaufgabenerledigung und die inhaltlich sehr ähnliche häusliche Aktivität der Prüfungsvorbereitung bildeten zusammen mit 97 Episoden den Kontext für die Hälfte aller 194 untersuchten Wertepisoden (vgl. Tabelle 7.1).

- In diesen standen primär fachlich-methodische Kompetenzen des Kindes (Zielbereich C) und - noch spezifischer - insbesondere Ressourcenstrategien sowie metakognitive Strategien (vgl. Friedrich \& Mandl, 1992) im Fokus der elterlichen Bedeutsamkeitszuschreibungen: So berichten die Elternteile in 24 
Episoden, wie sie gegenüber ihren Kindern die Bedeutung des Zeitpunkts und der Zeiteinteilung des Lernens, des kontinuierlichen Arbeitens, der angemessenen Prioritätensetzung zwischen Hausaufgaben und Freizeit oder des Nutzens von Lehrkräften, Peers und ihnen selber als Informations- und Unterstützungsquellen hervorgehoben haben. Fast ebenso häufig (21 Episoden) strichen sie die Bedeutung des Planens, Überwachens und Evaluierens des eigenen Lernens heraus: Konkret werden die Kinder in den entsprechenden Episoden zu erhöhter Selbständigkeit, Sorgfalt, Eigenständigkeit, Regelkonformität und Vollständigkeit bei der Hausaufgabenerledigung oder dem Vorbereiten auf Prüfungen motiviert.

- Auch aktivitäts- und umsetzungsorientierte Kompetenzen der Kinder (Zielbereich B) stehen im Kontext von Hausaufgaben und Prüfungsvorbereitungen im Zentrum elterlicher Wertregulationen: In 24 Episoden wurde die Bedeutung eines angemessenen Engagements beim häuslichen Lernen hervorgehoben («Raff dich auf!»), in je acht Episoden diejenige von Anstrengung («Bleib dran!»/«Sei fleißig!») und Wille («Überwinde dich und mach dich an die Arbeit!») sowie in fünf Episoden diejenige von Ausdauer («Halte durch!»).

- Eine untergeordnete Rolle spielten bei diesen Wertregulationen dahingegen Handlungsweisen des Kindes im Bereich sozial-kommunikativer und personaler Kompetenzen (Zielbereiche D und A): In vier Episoden wird die Bedeutung einer streitfreien Kommunikation mit den Eltern oder Peers während des gemeinsamen häuslichen Lernens betont und in drei weiteren Episoden die Bedeutung einer positiven Einstellung gegenüber Hausaufgaben herausgestrichen.

Der Übertritt bildete das andere große Thema in den Eltern-Kind-Dyaden (in 43 der 70 leistungsthematischen Episoden, $61.4 \%$ intra). Diesbezüglich zeigte sich (vgl. Tabelle 7.2), dass den Kindern in der Entscheidungsfindungsphase zwar stark die Bedeutung des Erreichens bestimmter Leistungsziele (Zielbereich E) - der Stellenwert guter oder besserer Noten (zwölf Episoden), des erwünschten Sekundarschultyps (zehn Episoden) - oder eines angemessenen Engagements - «das Beste geben, zu dem man fähig ist» o.ä. (fünf Episoden, Zielbereich B: aktivitätsund umsetzungsorientierte Kompetenzen) - deutlich gemacht wurde, dass es den Elternteilen aber auch wichtig war, die Bedeutung einer angemessenen Selbstpositionierung des Kindes gegenüber dem Übertrittsgeschehen zu betonen ( $«$ Sieh dich so!» bzw. «Sieh das Verfahren so!»): In insgesamt 16 Episoden, die dem Zielbereich personaler Kompetenzen (Zielbereich A) zugeordnet wurden, hatten die Eltern das Kind davon zu überzeugen versucht, dass es bedeutsam sei, auf einen 
bestimmten Sekundarschultyp zu aspirieren, den Status als zukünftige/r Sek-BSchüler*in zu akzeptieren, den Übertritt bzw. bestimmte Übertrittsereignisse wie Prüfungen, das Zeugnis und Gespräche mit der Lehrkraft als wichtig zu erkennen und sich allmählich auf die Anforderungen der Sekundarstufe einzustellen.

Es fällt auf, dass die Elternteile somit hauptsächlich von Wertregulationen berichtet haben, die die Selbstregulation beim häuslichen Lernen und die Zielausrichtung des Kindes bezüglich des von ihnen aspirierten Bildungsganges fokussierten. Bedeutsamkeitszuschreibungen, die im engeren Sinn einen fachspezifischen Fokus aufwiesen und den Stellenwert diesbezüglicher Informationsverarbeitungsstrategien betonten, traten in den Interviews dahingegen nur in sehr geringem Umfang auf (vgl. Tabelle 7.5) und wurden in keiner Episode im Kontext gemeinsamer Problemlöseprozesse bei Hausaufgaben, sondern stets im Kontext von Alltagsgesprächen über schulische Kompetenzen und Lernprozesse berichtet (vgl. Elternteile E11, S11, S12 und V12). So meint z. B. die Mutter E11 in Episode M026 (vgl. Anhang, Tabelle 9.1): «[...] Also ich sage immer, er sollte mehr lesen. Aber er findet, er könne ja gut Deutsch, er müsse nicht mehr lesen. Er liest ja da seine Hefte und Zeug. Aber ich habe gesagt:,Ich möchte, dass du ein Buch liest, das ist etwas anderes.'». Auch wenn es zu einem Teil der Ausrichtung des Interviews auf generalisierte Aspekte des Handelns und Wahrnehmens über die gesamten acht Monate der Übertrittszeit geschuldet sein mag, dass die Elternteile kaum von Situationen berichteten, in denen sie vor dem Kind spezifischere Informationsverarbeitungsstrategien hervorhoben, so widerspiegelt dies zum anderen Teil auch ihr Rollenverständnis, wenn es um die schulbezogene Unterstützung ihres Kindes geht: Das Erklären von Lösungswegen und von theoretischen Konzepten sowie das Vermitteln entsprechender domänenspezifischer Strategien erachteten die Eltern klar als Aufgabe der Lehrkraft. Auch die Mutter D11 und der Vater Z22, die sich bei Bedarf lustvoll der Hausaufgabenhilfe widmeten und sich Gedanken darüber machten, wie sie diese didaktisch optimieren könnten ${ }^{1}$ - die also mehr taten als nur vor Prüfungen das Vokabular in den Fremdsprachen oder Begrifflichkeiten in den Sachfächern abzufragen -, trauen sich dies lediglich in ausgewählten Domänen zu und berichten von Konflikten mit dem Kind, die sich daran entzündeten, dass gegenseitige Erwartungen bezüglich des methodischen oder kommunikativen Vorgehens nicht erfüllt wurden.

\footnotetext{
${ }^{1}$ So berichtet die Mutter D11 in Episode M009 (vgl. Anhang, Tabelle 9.1): «Gestern habe ich auch einen alternativen Weg finden müssen, weil ich gemerkt habe, dass es bei K01 bildlich nicht vorhanden ist. Und Prozentrechnen, ohne sich davon ein Bild machen zu können, liegt einfach nicht drin. Und da musste ich den Schulweg verlassen und sagen, ich nehme die alten [Rechen-]Klötze [wieder] hervor».
} 
Die in den Wertregulationen fokussierten Ziele zeigen, dass die 20 Elternteile bereit waren, die Rolle von Coaches zu übernehmen, die während der unsicheren Übertrittszeit darauf achteten, dass das Kind das Fernziel eines Übertritts in die aspirierte Abteilung nicht aus den Augen verlor, dass es sich der Bedeutung desselben für die eigene Entwicklung laufend klarer wurde und sich bewusst war, wie wichtig gute Noten dabei in den Kernfächern seien: Die verdichtete Bedeutsamkeitszuschreibung mit den in leistungsthematischen Gesprächen am häufigsten anvisierten Zielen lautete denn auch: «Es ist bedeutsam, dass du dich als zukünftige/r Sek-A-Schüler*in siehst, laufend gute Noten machst und das Ziel Abteilung A der Sekundarschule auch wirklich erreichst» (vgl. Abschnitt 7.1.1.6). Im Kontext lernthematischer Situationen äußerte sich die sich selbst zugedachte Rolle der Eltern als Coaches in bewusstheitsstiftenden Hinweisen auf die Bedeutung eines besseren Umgangs mit Zeitressourcen und potentiellen Informationsund Unterstützungsquellen sowie im antreibenden Begleiten, wenn die Kinder in den jeweiligen Situationen die notwendige kognitive oder motivational-affektive Ausrichtung auf die Aufgaben nicht aufbrachten. Die verdichtete prototypische Bedeutsamkeitszuschreibung lautete hierbei: «Es ist bedeutsam, dass du die Zeit einteilst, uns und andere Hilfsquellen nutzt und dich aufraffst und engagierst» (vgl. Abschnitt 7.1.1.6). Wie das Kind dies bewerkstelligen soll, wurde ihm gegenüber oftmals nicht weiter ausgeführt.

\subsubsection{In den elterlichen Wertregulationen eingesetzte Argumente}

Bezogen auf die Argumentationsstrukturen der 194 Wertregulationen, die entlang des Achtfelderschemas des Kategoriensystems «Elterliche Strategien der verbalen Wertvermittlung» (vgl. Abbildung 5.4) hinsichtlich der drei Dimensionen Aufgabenwert (Zweckmäßigkeit vs. Wesentlichkeit), Valenz (positiv vs. negativ) und Lokus (internal vs. external) codiert wurden, zeigte sich, dass die Elternteile in $75 \%$ der Episoden eines der folgenden vier Muster einsetzten:

- In jeder dritten Wertregulation begründeten die Elternteile die Bedeutsamkeit eines bestimmten schulbezogenen Handelns oder eines Leistungsereignisses gegenüber ihrem Kind mit sozialen Normen und entsprechenden interpersonalen Erwartungen: Konkret wiesen 62 Argumente (32.0\% overall) den Begründungstyp positive externale Wesentlichkeit (Ee+) auf (vgl. Tabelle 7.3 und Tabelle 7.4), wobei die Kinder am häufigsten (in 45 der 62 Argumente) 
an die Pflichten, die sich aus ihrer Rolle als Schüler*innen ergäben, erinnert wurden: «weil du das als Schüler*in - insbesondere in der aktuellen Übertrittsphase - einfach musst!».

- Am zweithäufigsten setzten die Elternteile den Begründungstyp negative externale Zweckmäßigkeit (Oe-) in ihren Wertregulationen ein (33 Argumente, $17.0 \%$ overall): Sie begründeten die Bedeutsamkeit von Handlungs- und Leistungszielen mit deren Instrumentalität zur Verhinderung andernfalls von außen drohender aversiver Konsequenzen, vor allem in Form eines nicht wunschgemäßen Übertrittsentscheids, von schlechter werdenden Prüfungs- und Zeugnisnoten oder von Problemen in den Beziehungen zu Lehrkräften und Peers, aber auch in Form von Bestrafungen durch sie selber (Tabelle 7.3 und Tabelle 7.4). Mit anderen Worten operierten die Elternteile mit Warnungen, selten auch mit Drohungen, wenn sie den Kindern die Bedeutsamkeit von Zielen mit solchen Argumenten zu verdeutlichen suchten. Das am häufigsten eingesetzte Argument lautete hierbei: «weil du sonst den gewünschten Übertrittsentscheid nicht erreichst» (in 16 von 33 Argumenten).

- Am dritthäufigsten setzten sie den Begründungstyp positive internale Zweckmäßigkeit (Oi+) ein (26 Argumente, $13.4 \%$ overall). Die Elternteile stellten mit diesen Argumenten die von ihnen als bedeutsam erkannten Handlungsund Leistungsziele gegenüber dem Kind als nützlich für seine kognitive Entwicklung sowie für sein motivational-affektives Erleben dar. Das dabei am häufigsten eingesetzte Argument lautete sinngemäß: «weil du so fachlich besser werden kannst» (in 15 von 26 Argumenten).

- Der vierthäufigste Begründungstyp positive externale Zweckmäßigkeit (Oe+), der sich inhaltlich vom Begründungstyp Oi+nur dadurch unterscheidet, dass hier nicht internale, sondern externale positive Konsequenzen in Form handfester Belohnungen, günstiger Beurteilungen, Zugangsberechtigungen, Lob oder Hilfestellungen in Aussicht gestellt werden, wurde von den Elternteilen in 22 Argumenten (11.3\% overall) eingesetzt. Das prototypische Argument lautete hierbei: «weil du so eine günstige Ausgangslage für den Übertritt und deine Berufswahl erreichen kannst» (in 12 von 22 Argumenten).

Deutlich wird, dass die Elternteile mit den beiden Begründungstypen positive externale Wesentlichkeit (Ee+) und negative externale Zweckmäßigkeit (Oe-) in 95 von 194 Wertepisoden (49.0\% overall) eine Argumentationsstrategie eingesetzt haben, die den Kindern mehr oder weniger explizit einen geringen oder eher geringen Entscheidungsspielraum hinsichtlich der Befolgung eines Verhaltensoder Leistungsziels signalisierte: «Es ist bedeutsam, dass du das Ziel erreichst, weil du einfach musst» und «Es ist bedeutsam, dass du das Ziel erreichst, 
weil du sonst negative Konsequenzen gewärtigen musst». Mit den beiden Argumentationsstrategien wiesen die Elternteile gegenüber dem Kind explizit auf die Erwartungen des sozialen Umfelds bzw. auf aversive Aspekte hin: Die für den Begründungstyp positive externale Wesentlichkeit (Ees+) charakteristischen Formulierungen «nicht umhinkommen», «müssen» und «verantwortlich sein» verweisen auf die von den Elternteilen hervorgehobenen Anforderungen, die sie als wesentlich erachteten im Zusammenhang mit der jeweils im Fokus stehenden Rolle des Kindes als Schüler/-in, als Person in einem Statusübergang oder als Tochter bzw. Sohn (vgl. Tabelle 7.3 und Tabelle 7.4). Dem Kind wurde verbal ein Rollenmerkmal und eine damit zusammenhängende Pflicht signalisiert, entsprechend zu handeln, - und somit immer auch angedeutet, dass es bei Zuwiderhandlung in Konflikt mit signifikanten Personen und Institutionen geraten würde (vgl. Abschnitt 5.6.2.3).

Für den Begründungstyp negative externale Zweckmäßigkeit (Oe-) ist das Adverb «sonst» charakteristisch. Hier funktionieren die Wertregulationen direkt über Bedrohungsszenarien. Zwar signalisiert der Einsatz von Zweckmäßigkeitsargumenten stets die Absicht, beraten zu wollen (vgl. Abschnitt 5.6.2.3), doch dürften die meisten Kinder die verbalisierten aversiven Konsequenzen durchaus als Einschränkung ihres Entscheidungs- bzw. Handlungsspielraums auffassen und vermutlich wahrnehmen, dass die Eltern die Bedeutsamkeit des entsprechenden Handlungs- oder Leistungsziels als hoch veranschlagen. In welchem Maß diese negativ-valenten Begründungen aufseiten der Kinder zu negativen Emotionen wie Angst oder aber Ärger führten, dürfte v. a. davon abhängig sein, inwiefern sie dem im jeweiligen Argument genannten Zweck (z. B. den Übertritt in die Abteilung A der Sekundarschule schaffen) selber eine hohe Bedeutung beimaßen, und davon, für wie wahrscheinlich sie das Eintreffen der angedrohten negativen Konsequenzen hielten (vgl. Abschnitt 5.6.2.1).

Bei den beiden Begründungstypen positive internale Zweckmäßigkeit (Oi+) und positive externale Zweckmäßigkeit (Oe+), die zusammen in knapp einem Viertel der Wertregulationen als Argumentationsstrategie eingesetzt wurden, eröffnete sich den Kindern dahingegen ein wesentlich größerer Spielraum für eigene Entscheidungen, weil beide ein appetitiv-beratendes Moment in sich tragen: Das Kind wurde verbal für ein bestimmtes Handeln oder eine bestimmte Leistung motiviert, indem ihm die positiven internalen bzw. externalen Konsequenzen geschildert wurden, die sich bei der Erreichung des betreffenden Ziels eröffnen würden. Zumindest vordergründig signalisierten die Elternteile eine geringe Verbindlichkeit, indem sie beratend mit der Instrumentalität des angesprochenen Handlungs- oder Leistungsziels zur Erlangung größerer, dem Kind wohl wichtigere Ziele zu locken wussten (vgl. Abschnitt 5.6.2.3). 


\subsubsection{Fokussierte schulbezogene Ziele der elterlichen Kontrollregulationen}

Die strukturierenden qualitativen Inhaltsanalysen, denen die 104 Kontrollepisoden auf der Basis der Kategoriensysteme «Thema der Gesprächssequenz» (vgl. Tabelle 6.7) und «Zielbereiche» (vgl. Tabelle 6.8) unterzogen wurden, förderten zutage, dass die Elternteile vornehmlich von evaluativen Feedbacks gegenüber den Kindern berichten, die wie schon bei den Wertregulationen vor allem im Rahmen von häuslichen Gesprächen über Hausaufgaben und den Übertritt sowie - in geringerem $\mathrm{Ma} ß$ - in Gesprächen über Prüfungsergebnisse und über Erlebnisse in der Schule erfolgt waren.

Bezüglich der Hausaufgabenerledigung und Prüfungsvorbereitungen, die mit 47 Episoden das Hauptthema in den 60 lernthematischen Episoden bildeten (vgl. Tabelle 7.5), ergaben sich folgende Befunde:

- Am häufigsten standen Ziele im Fokus der elterlichen Feedbacks, die sich fachlich-methodischen Kompetenzen (Zielbereich C) zuordnen ließen: In 18 Episoden beurteilten die Elternteile Handlungsweisen des Kindes, die das Planen, Überwachen und Evaluieren des eigenen Lernens und somit metakognitive Lernstrategien (vgl. Friedrich \& Mandl, 1992) betrafen: Konkret wurde in den entsprechenden Episoden beurteilt, wie effizient, selbständig, sorgfältig, verstehensorientiert und analytisch die Hausaufgabenerledigung oder das Lernen auf anstehende Prüfungen erfolgte. Ebenso beurteilten die Elternteile in weiteren zehn Episoden das Ressourcenmanagement des Kindes: Die Zeiteinteilung bei längerfristigen Aufgabestellungen sowie das Zurückgreifen auf Hilfsmittel wie das Wörterbuch oder das Internet wurden hierbei thematisiert. Eine untergeordnete Rolle spielten dahingegen die ebenfalls dem Zielbereich $\mathrm{C}$ zugeordneten Handlungsweisen des Kindes, die die Verarbeitung des Lernstoffs betrafen: Konkret fanden sich lediglich zwei Stellen, in denen die Elternteile das Memorieren, Organisieren oder Elaborieren der im Rahmen von Hausaufgaben zu internalisierenden Informationen durch das Kind beurteilt hätten («Du hast das Ausrechnen von Beträgen im Kopf gut/schlecht im Griff» und «Du hast das Analysieren von Sprache mittels Grammatik gut/schlecht im Griff»).

- Am zweithäufigsten standen im Kontext von Hausaufgaben motivationale Aspekte der Kinder und somit aktivitäts- und umsetzungsorientierte Kompetenzen (Zielbereich B) im Zentrum der elterlichen evaluativen Feedbacks: In neun Episoden wurde das Engagement des Kindes beim häuslichen Lernen beurteilt, in je zwei Episoden der Wille (sich überwinden und an die Arbeit machen) und die Anstrengung (dranbleiben). 
- Am dritthäufigsten wurden bei Hausaufgaben und Prüfungsvorbereitungen gemäß den Aussagen der Elternteile sozial-kommunikative Aspekte (Zielbereich D) in den evaluativen Feedbacks thematisiert: In sieben Episoden wird die Qualität der Zusammenarbeit mit Eltern oder Freunden sowie das Hilfesuchverhalten des Kindes beurteilt.

Bezüglich des Übertritts, des anderen zentralen schulbezogenen Gesprächsgegenstandes in den Eltern-Kind-Dyaden (in 31 der 44 leistungsthematischen Episoden), zeigt sich (vgl. Tabelle 7.6) Folgendes:

- Im Fokus der elterlichen Kontrollregulationen stand vor allem (in 14 der 31 spezifisch übertrittsbezogenen Episoden) die Wahrscheinlichkeit der Zuteilung zum erwünschten Sekundarschultyp bzw. das Erfüllen der diesbezüglichen Bedingungen (Zielbereich E).

- Am zweithäufigsten fokussierten sie Ziele, die personalen Kompetenzen (Zielbereich A) zuzuordnen waren: In neun der 31 Episoden beurteilten die Elternteile die Angemessenheit der Situationseinschätzung durch die Kinder. Unter anderem versuchten sie ihnen dabei klar zu machen, dass sie den Anforderungsgrad der Abteilung A verkennen oder deren Bedeutung für die eigene berufliche Zukunft unterschätzen würden.

- Auch Anstrengung und Engagement - und somit Ziele im Bereich aktivitätsund umsetzungsorientierter Kompetenzen (Zielbereich B) standen in neun Episoden im Zentrum des evaluativen Feedbacks zum übertrittsbezogenen Handeln des Kindes (vgl. Tabelle 7.6).

Hinsichtlich der anderen beiden schulbezogenen Themen in den Elternhäusern zeigt sich ferner, dass in den Episoden, die sich mit Prüfungsergebnissen beschäftigen, vor allem das Engagement und die Anstrengung des Kindes bei der Prüfungsvorbereitung (Zielbereich B) beurteilt wurde (in sechs von 13 entsprechenden Episoden) (vgl. Tabelle 7.6). In den Episoden, in denen das Handeln des Kindes im Unterricht zum Gesprächsgegenstand wird, fokussierten die Eltern in ihren Kontrollregulationen vor allem auf sozial-kommunikative Aspekte (Zielbereich D) (in sechs von acht entsprechenden Episoden): Beurteilt wurde von ihnen die Gestaltung der Beziehung zu Lehrkräften und zu den Klassenkamerad*innen sowie der Umgang mit Konflikten mit diesen Personengruppen (vgl. Tabelle 7.5).

Die Befunde machen deutlich, dass sich die 20 Elternteile hauptsächlich in Situationen, in denen das Kind allein oder zusammen mit ihnen an den Hausaufgaben saß, oder aber im Zuge gemeinsamer Gespräche über den Übertritt anschickten, bestimmte Aspekte seines Lern- und Leistungshandelns vor ihm zu 
evaluieren. Sofern sie das häusliche Lernen thematisierten, standen wiederum Aspekte der Selbstregulation im Zentrum der elterlichen Beurteilungen: seine metakognitiven Strategien, seine Ressourcenstrategien oder aber seine Motivation. Fasst man die von den 20 Elternteilen laut eigenen Erzählungen am häufigsten beurteilten Handlungsziele $\mathrm{zu}$ einer verdichteten prototypischen Aussage zusammen, so lautet diese: «Du hast das selbständige, sorgfältige, effiziente und lernproduktive Erledigen deiner Schularbeiten gut/schlecht im Griff».

In leistungsbezogenen Gesprächsanlässen, die sich vornehmlich um den Übertritt drehten, waren die Elternteile vor allem damit beschäftigt, dem Kind ein Bild davon zu vermitteln, inwieweit es zum jeweiligen Zeitpunkt die Anforderungen für die aspirierte Abteilung der Sekundarschule erfülle und wie angemessen seine eigene Einschätzung sei. «Du hast das Erfüllen der Bedingungen für den Übertritt in die Abteilung A der Sekundarschule sowie das Einschätzen der Anforderungen und der Tragweite dieses Übertritts gut/schlecht im Griff», lautete hier die verdichtete prototypische Aussage der 20 Elternteile.

Die Ähnlichkeiten der Ziele, die in den wert- und in den kontrollbezogenen Kommunikationssituationen anvisiert wurden, kann angesichts der Tatsache, dass es oft dieselben Textstellen waren, in denen beide Regulationstypen kombiniert auftauchten, kaum erstaunen. Wie in Abschnitt 5.6.2 erwähnt, können die untersuchten Handlungsepisoden mit Blick auf die Arbeiten von Hattie und Timperley (2007) sowie Kluger und DeNisi (1996) als Ganzes auch als Schilderungen von Rückmeldesituationen verstanden werden, in denen die Eltern von ihren Feed Back-Moves (elterliche Kontrollregulationen) sowie - oft noch im gleichen Satz - von ihren Feed Up- und Feed Forward-Moves (elterliche Wertregulationen) berichten: Bedeutsamkeitszuschreibungen wurden von den Eltern mehrheitlich in Situationen vorgenommen, in denen sie problematische Aspekte im Denken und Handeln des Kindes erkannten, und oftmals - wenn auch nicht immer - benannten sie das in ihren Augen Defizitäre explizit, indem sie ein entsprechendes negativ-valentes evaluatives Feedback abgaben (vgl. Abbildung 7.6). Ebenso finden sich auch einzelne elternberichtete Episoden, in denen beide Regulationsarten in positiv-valenten Gesprächssituationen kombiniert auftraten: Die Elternteile benannten einen Aspekt, den das Kind gut im Griff habe und betonten die Bedeutsamkeit, weiterhin entsprechend zu handeln.

Das Zusammenspiel von verbalen Wert- und Kontrollregulationen wurde in der vorliegenden Arbeit, die sich auf Handlungsschilderungen abstützt, nicht genauer untersucht. Mit Blick auf die Interaktionen, die zwischen den wert- und kontrollbezogenen Kognitionen bei Individuen bestehen (vgl. Kapitel 5), stellt 
das Beschreiben und Erklären des Zusammenspiels zwischen value interventions und evaluative feedback aber ein wichtiges Desiderat in der relativ jungen Motivierungsforschung dar (vgl. Hulleman \& Barron, 2016).

\subsubsection{In den elterlichen Kontrollregulationen eingesetzte Argumente}

Die Analysen haben offengelegt, dass die 20 Elternteile in den von ihnen beschriebenen 104 Kontrollregulationen mit insgesamt 140 attributionalen Argumenten versucht haben, ihren Kindern gegenüber zu unterstreichen, warum diese ein bestimmtes lern- oder leistungsbezogenes Ziel genügend bzw. ungenügend im Griff hätten (vgl. Tabelle 7.7 und Tabelle 7.8). Diese Argumente wurden mit Hilfe des auf der Basis von Weiners Klassifikationsschema kausaler Attributionen (1994, S. 271) geschaffenen Kategoriensystems «Elterliche Strategien der verbalen Kontrollvermittlung» (vgl. Abbildung 5.3) hinsichtlich der vier Dimensionen Lokus (internal vs. external), Stabilität (stabil vs. variabel), willentliche Beeinflussbarkeit (tief vs. hoch) und Valenz des Arguments (positiv vs. negativ) codiert.

Die Untersuchung der 140 Argumente entlang dieser vier Dimensionen ergab,

- dass die 20 Elternteile ihren Kindern in überwiegendem Maß (in 117 Argumenten, $83.6 \%$ overall) internale Aspekte, also solche, die bei diesen selber lagen, vor Augen gehalten hatten,

- dass die Mehrheit dieser internalen Aspekte (81 Argumente, $69.2 \%$ intra) das Handeln des Kindes - also ein prozessualer, willentlich veränderbarer Faktor betraf,

- dass sie mehrheitlich (95 der 140 Argumente, $67.9 \%$ overall) auf stabile Aspekte verwiesen und

- dass die überwiegende Mehrheit, nämlich 101 der140 Argumente (72.1\% overall), negativ gefärbt waren und somit auf Aspekte zeigten, die in den Augen der Elternteile problematisch waren.

Mit Blick auf die aus den vier Dimensionen gebildeten kontrollbezogenen Begründungstypen (vgl. Abbildung 5.3) traten in den 104 Kontrollregulationen großmehrheitlich (in 69 Episoden, $66.3 \%$ ) die folgenden drei Argumentationsmuster allein oder in Kombination auf (vgl. Abbildung 7.6): 
- Bei weitem am häufigsten (in 48 von 140 Argumenten, $34.3 \%$ overall) setzten die Elternteile den Begründungstyp stabiles negatives Handeln des Kindes (KHs-) ein. Somit wurde in jedem dritten Argument ein Aspekt des Handelns des Kindes thematisiert, der zwar als dauerhaft problembehaftet dargestellt wurde, aber grundsätzlich durch das Kind willentlich veränderbar und für dieses somit nicht gänzlich unkontrollierbar war (vgl. Abschnitt 5.3.3.2). Würde das Kind den angesprochenen Handlungsaspekt optimieren, so lautete die dabei transportierte Botschaft, könnte es das entsprechende Lernoder Leistungsziel in den Griff bekommen. Gruppiert man die in Tabelle 7.7 und Tabelle 7.8 genannten konkreten Aussagen inhaltlich, ergibt sich für den Begründungstyp KHs- die folgende verdichtete prototypische Aussage der 20 Elternteile: «weil du ständig zu wenig intensiv und kontinuierlich arbeitest und vor der ernsten Situation des Übertritts die Augen verschließt» (in 23 von 48 Argumenten).

- Am zweithäufigsten (in 19 Argumenten, $13.6 \%$ overall) fand sich der Begründungstyp variables negatives Handeln des Kindes (KHv-). Die Elternteile argumentierten hierbei mit mangelhaften Handlungsmerkmalen des Kindes, die hin und wieder aufträten. Mit der explizit angesprochenen Variabilität des Auftretens - «weil du es manchmal (noch) falsch machst» - brachten sie gegenüber ihrem Kind implizit aber immer auch zum Ausdruck, dass es ein bestimmtes lern- oder leistungsbezogenes Ziel mit erhöhter Aufmerksamkeit und dem notwendigen Willen in den Griff kriegen könne bzw. ab und an bereits unter Kontrolle habe (vgl. Abschnitt 5.3.3.2). Die verdichtete prototypische Aussage lautete hier: «weil du manchmal zu wenig intensiv arbeitest bzw. ein schlechtes Vorgehen wählst» (in elf von 19 Argumenten).

- Am dritthäufigsten (17 Argumente, $12.1 \%$ overall) setzten die Elternteile den Begründungstyp variable negative Bedingungen beim Kind (KBv-) ein. Charakteristisch für diesen Begründungstyp ist es, dass ein hinderliches Bedingungsmerkmal beim Kind als temporär (noch) auftretend dargestellt wird. Die Botschaft lautet somit: «Zwar wirst du zeitweise von diesen Umständen geplagt, aber wenigstens nicht immer bzw. zunehmend weniger. Du hast das Lern- oder Leistungsziel zwar lediglich mäßig im Griff, doch ist die Situation nicht aussichtslos.» Diese Argumentationsstrategie signalisiert zwar eine geringe willentliche Beeinflussbarkeit des betreffenden Ziels oder Handlungsaspekts, gleichzeitig erscheint die Lage durch das angedeutete lediglich sporadische Auftreten der hindernden Faktoren nicht gänzlich hoffnungslos (vgl. Abschnitt 5.3.3.2). Das verdichtete prototypische Argument der Elternteile lautete hierbei: «weil du ab und zu (noch) eine unzureichende Einstellung hast bzw. noch kindlich-unreif denkst» (in 12 von 17 Argumenten). 
Die Befunde zu den drei am häufigsten eingesetzten Strategien, mit denen die Elternteile gemäß eigener Erzählungen ihren Kindern zu verdeutlichen suchten, inwiefern diese die angesprochenen schulische Ziele im Griff hätten, lassen vermuten, dass ihnen wenigstens intuitiv klar war, wie heikel evaluative Feedbacks mit Blick auf den Selbstwert und somit bezüglich des emotionalen Erlebens und der Motivation sein können: Einerseits fühlten sie sich in ihrer Rolle als Eltern verpflichtet, den Kindern ein möglichst adäquates Bild ihrer Einschätzung seiner lern- und leistungsbezogenen Situation abzugeben - wobei die Evaluation derselben in 80 der 104 Kontrollregulationen $(76.9 \%)$ negativ ausfiel («Du hast es schlecht in Griff», vgl. Abschnitt 7.2.3.2). Andererseits vermieden es die Elternteile meist, den in motivationaler Hinsicht besonders problematischen Begründungstyp stabile negative Bedingungen beim Kind (KBs-) einzusetzen. Mit zehn von 140 Argumenten (7.1\% overall) gehörte dieser Begründungsansatz, bei dem die fehlende Kontrolle eines schulischen Ziels gegenüber dem Kind mit in ihm liegenden, sich negativ bemerkbar machenden dauerhaften Umständen erklärt wird $^{2}$, klar nicht zu den Kernstrategien der Elternteile. Sie vermieden es somit, maladaptive Attributions-Emotions-Motivations-Performanz-Pfade $\mathrm{zu}$ initiieren und zu fördern (vgl. Abschnitt 5.3.3.2), die bei negativ-valenten Ergebnissen oder Feedbacks in Selbst- oder Fremdattributionen auf willentlich nicht beeinflussbare, internale und stabile Faktoren ihren Ausgang nehmen, tiefe Kontrolleinschätzungen und entsprechende negative Emotionen erzeugen und mit unliebsamen Effekten auf den Selbstwert einhergehen, was wiederum in ungünstigen motivationalen Zuständen und in entsprechend ungenügenden Lernhandlungen resultiert, welche schließlich in erneute Misserfolge bzw. Kritik münden (vgl. Perry \& Hamm, 2017, S. 71). Vielmehr setzten die Elternteile in ihren negativ-valenten Feedbacks solche attributionalen Argumente ein, die dem Kind wenigstens ein Mindestmaß an Zuversicht und Selbstwertschutz ermöglichten: So signalisiert der am häufigsten benutzte Begründungstyp stabiles negatives Handeln des Kindes (KHs-) zwar die Dauerhaftigkeit des ungünstigen Zustandes, gleichzeitig wird aber mit dem Handeln ein willentlich veränderbarer Aspekt angesprochen. Mit dem am zweithäufigsten eingesetzten Begründungstyp variables negatives Handeln des Kindes (KHv-) wird in Anbetracht der negativen Beurteilung, die der Elternteil vermitteln möchte, sogar optimal attribuiert, insofern als variable und willentlich veränderbare Faktoren angeführt werden, die sich immer wieder als zentrale Elemente eines adaptiven Zuschreibungs-Handlungs-Pfads (vgl.

\footnotetext{
${ }^{2}$ Die verdichtete prototypische Aussage der Elternteile lautete in neun der zehn diesbezüglichen Argumente: «weil du über ungünstige Persönlichkeitsmerkmale verfügst bzw. eine dauerhaft schlechte Einstellung der Sache gegenüber aufweist» (vgl. Abschnitt 7.2.2.3).
} 
Abschnitt 5.3.3.2) erwiesen haben. Selbst beim Begründungstyp variable negative Bedingungen beim Kind ( $\left.\mathrm{KBv}^{-}\right)$, der am dritthäufigsten eingesetzt wurde und der wegen der Attribuierung auf ein strukturelles, im Kind liegendes Merkmal und der damit einhergehenden geringen willentlichen Beeinflussbarkeit als problematischer Argumentationsansatz betrachtet werden muss, haben die Elternteile mit dem Aspekt der Veränderlichkeit («du verfügst insofern noch über hinderliche personale Merkmale, als du kindlichen Ideen nachhängst und dir die notwendige Reife fehlt») ein Element in ihre Argumentationen eingebaut, das eine günstige Entwicklung in naher Zukunft impliziert und somit trotz negativer Evaluation Zuversicht signalisiert.

\subsection{Die vier Typen des verbal-appellativen Motivierungshandelns bei einem unklaren Übertritt: Bedingungen, Chancen, Risiken}

Welcher individuelle Stil des verbal-appellativen Motivierens lässt sich bei denjenigen 18 Eltern feststellen, die nicht nur hinsichtlich der verbalen Gestaltungsmerkmale ihrer wert- und kontrollbezogenen Botschaften, sondern auch bezüglich der kommunikativen und affektiven Charakteristiken ihrer Appelle an das Kind in der unsicheren Übertrittszeit untersucht wurden?

Welche Typologie verbal-appellativen Motivierungshandelns im Kontext eines unklaren Übertrittsentscheids lässt sich schließlich aus den individuellen Stilen der Elternteile gewinnen und mit welchen Bedingungsmerkmalen, Chancen und Risiken sind die einzelnen Handlungstypen verbunden?

Zur Beantwortung der fallspezifischen Forschungsfrage 3 nach dem individuellen Stil des verbalen Motivierens, den die 18 Eltern während der Übertrittszeit praktiziert hatten, wurden jeweils alle Interviewstellen eines Elternteils, die wertund kontrollbezogene Regulationen sowie die Schilderungen häuslicher Kommunikationssituationen nach einem Erfolg oder Misserfolg bei einer Mathematikprüfung enthielten (vgl. Abschnitt 6.4.1), einem höher-inferenten Rating bezüglich der folgenden sieben Qualitätsdimensionen unterzogen: a) Betonung von Wesentlichkeit, b) Betonung positiver Aspekte, c) Betonung internaler Aspekte, d) zugeschriebene Kontrolle, e) Diskursivität, f) Assertivität sowie g) emotionale Zuwendung (vgl. Abschnitt 6.4.3).

In Tabelle 7.14 wurde der aus den genannten Dimensionen gebildete individuelle Stil des verbal-appellativen wert- und kontrollbezogenen Handelns für jeden Elternteil in Form des jeweiligen numerischen Merkmalsstrings sowie in Textform 
als Fallprofile (vgl. Spalte 9 in Tabelle 7.14) dargestellt. Letztere stellen Verdichtungen der ausführlichen Fallrekonstruktionen dar, die zuvor bezüglich jeder der sieben Dimensionen in den Abschnitten 7.3.1 bis 7.3.4 entwickelt worden sind.

Die fallspezifischen Analysen haben gezeigt, dass unter den 18 Elternteilen bezüglich der sieben Dimensionen 16 verschiedene Merkmalskonfigurationen existierten. Lediglich die Elternteile R12 und V11 sowie die Elternteile M11 und Z31 wiesen während der Übertrittszeit je kongruente Motivierungsstile auf (vgl. Abschnitt 7.3.5).

Mit Blick auf die gruppenspezifische Fragestellung 4 wurden die 18 Profile bzw. die ihnen zugrundeliegenden sieben Dimensionen mittels der Hauptkomponentenanalyse zuerst einer Dimensionsreduktion unterzogen (vgl. Abschnitt 6.4.4.1). Dabei offenbarte sich, dass sich die untersuchten Elternteile nach drei grundlegenden Dimensionen ihres verbalen Motivierungshandelns positionieren ließen: nach dem Grad ihrer Normorientierung, nach dem Grad ihrer Kindorientierung sowie nach dem Grad ihrer Durchsetzungsorientierung (vgl. Abschnitt 7.4.1). Die anschließende Clusteranalyse (vgl. Abschnitt 6.4.4.2) zeigte ferner, dass in der Stichprobe vier Typen des verbal-appellativen Motivierungshandelns während der unsicheren Übertrittszeit unterschieden werden konnten: 1. Diskursives Warnen vor den Folgen, 2. Unverbindliches, beschwichtigendes Hinweisen auf die Notwendigkeiten, 3. Ungeschminktes und schonungsloses Vermitteln der negativen leistungsbezogenen Einschätzung sowie 4 . Standfestes, diskursives Überzeugenwollen mittels gewinnender Argumente (vgl. Abschnitt 7.4.2).

Im Folgenden sollen die charakteristischen Merkmale jedes Handlungstyps am Beispiel eines jeweils besonders repräsentativen Fallprofils nochmals skizziert werden und mit Bezug zu den in Kapitel 5 erläuterten Zusammenhängen und Befunden, aber auch mit Blick auf die spezifischen Umstände der einzelnen Eltern-Kind-Dyaden, die ihnen zugeordnet sind, hinsichtlich ihrer mutmaßlichen Effekte auf die Motivation und das emotionale Erleben des Kindes diskutiert werden.

\subsubsection{Motivierungstyp 1: Diskursives Warnen vor den Folgen}

Die Gruppe von fünf Elternteilen, die den Motivierungstyp «Diskursives Warnen vor den Folgen während der Übertrittszeit» praktiziert hatte, setzte sich aus den Müttern D11, H11, H12, und Z12 sowie aus dem Vater V12 zusammen (vgl. Tabelle 7.16). Ihre Kinder waren die Mädchen K01, K05, K15 und die beiden Jungen K06 und K14 (vgl. Tabelle 4.4). 
Das Charakteristische am Motivierungsstil dieser Elternteile bestand darin, dass sie bezüglich der grundlegenden Dimension «Normorientierung» anders handelten als die überwiegende Mehrheit der übrigen Elternteile (vgl. Abbildung 7.7 und Abbildung 7.9). Typischerweise begründeten sie die Bedeutsamkeit schulischer Ziele nicht mit positiv-valenter Wesentlichkeit, («..., weil du das einfach musst») oder positiv-valenter Zweckmäßigkeit («..., weil du so ein wichtiges Ziel erreichst»), sondern indem sie ihrem Kind die aversiven Folgen vor Augen hielten, die es im Falle des Nichtbefolgens des von ihnen als bedeutsam markierten Lern- oder Leistungsziels zu gewärtigen habe. Abgesehen von der Mutter D11, die ihrer Tochter K01 aversive Konsequenzen bezüglich internaler Aspekte nannte - («weil du so mehr lernst», «weil du dich dann besser fühlst»-, warnten die übrigen Elternteile ihre Kinder vor allem vor negativen Folgen für den (externalen) Übertrittsentscheid.

Ein weiteres Merkmal des verbalen Motivierungshandelns aller fünf Elternteile bestand darin, dass sie bei ihren Wert- und Kontrollregulationen grundsätzlich diskursiv vorgingen: Sie waren darum bemüht, ihre Zuschreibungen mit denjenigen ihres Kindes abzugleichen, dessen Sichtweise zu erfahren und die eigene bei Bedarf genauer zu erklären.

Hinsichtlich der übrigen Stilkomponenten zeigte sich, dass diese Eltern mit Ausnahme der Mutter Z12 ihren Kindern eine eher geringe Kontrolle der Übertrittssituation (2) zuschrieben, dass sie mit Ausnahme der Mutter H11 eine eher hohe Assertivität (3) an den Tag legten und durchgängig mit hoher (3) bis sehr hoher (4) emotionaler Zuwendung auf Erfolge oder Misserfolge des Kindes reagierten (vgl. Tabelle 7.16).

Der mit Blick auf die Ausprägungen seiner Stilmerkmale am durchschnittlichsten handelnde Elternteil dieser Gruppe war der Vater V12 (vgl. Abschnitt 7.4.2). Das verbal-appellative Handeln der Eltern des Motivierungstyps 1 lässt sich folglich an seinem Fallprofil gut illustrieren und diskutieren:

V12 führte zum Zeitpunkt der Erhebung zusammen mit seiner Frau einen landwirtschaftlichen Betrieb und besaß neben seinem Sohn K14 noch ein weiteres jüngeres Kind. Die vier Familienmitglieder sind in der Schweiz geboren und aufgewachsen. Der Vater V12 hat das Gymnasium mit der Matura abgeschlossen und die Mutter hat die Abteilung A der Sekundarschule besucht. Beide haben eine berufliche Ausbildung, der Vater V12 hat diese mit dem Meistertitel beendet, der ihn befähigt, Lehrlinge auszubilden (vgl. Tabelle 4.1. und Tabelle 4.2). Der Sohn K14, der im Halbjahreszeugnis der 6. Klasse in Mathematik die Note 4.5 und in Deutsch die Note 4.0 aufwies, litt an einer leichten Legasthenie (vgl. Tabelle 4.4). Er wurde am Ende der Erhebungszeit in die Abteilung B eingeteilt, war aber einer der beiden Kinder der Stichprobe, die bereits zum ersten «Umstufungstermin» in der Sekundarschule in die anspruchsvollere Abteilung A umgeteilt wurden (vgl. Abschnitt 3.3). 
Bezüglich seiner Wertzuschreibungen wies der Vater V11 die für die Elterngruppe charakteristische Merkmalskombination Betonung von Zweckmäßigkeit (2), Betonung negativer Konsequenzen (2) sowie Betonung externaler Aspekte (2) auf (vgl. Tabelle 7.10): Er zeigte sich gegenüber seinem Sohn immer wieder beratend, mahnend und warnend und versuchte diesem die Nützlichkeit von Lernen, Arbeitsmethoden und Unterricht für das Lösen von Alltagsproblemen (Episode M137, vgl. Anhang, Tabelle 9.1), für die persönliche Entwicklung (M148, M151), für das persönliche Wohlbefinden (M160, M161, M163), namentlich aber für die Berufswahl und das spätere Arbeitsleben (M131, M139, M147) darzulegen. Im Verlauf der Übertrittszeit wurden sich die Eltern, die Klassenlehrerin L07 sowie K14 einig, dass letzterer erst einmal in die Abteilung B übertreten sollte:

«Ich denke auch die Einstufung, die hat K14 auf eine Art auch wieder beruhigt. Es ist jetzt klar gewesen. Wir haben ihm zuvor gesagt: 'Das Ziel wäre ja sicher B.' Wir haben ja auch gesehen, dass das A wahrscheinlich eher eine Stufe zu hoch ist. Und für ihn selber hatten wir auch das Gefühl, dass er ein wenig gefestigt und beruhigt ist. Jetzt ist das klar. Es war dann eher ein bisschen die Gefahr, dass er- ich habe ihm dann mal gesagt: 'Das heißt jetzt nicht, dass du wegen dem zurücklehnen musst und noch weniger machst.'» (M134).

Auch wenn Zweckmäßigkeitsargumente überwogen, wurde K14 wie in der zitierten Stelle auch immer wieder an seine Pflichten als Schüler erinnert und es wurde ihm signalisiert, dass er sich als jemanden erkennen müsse, der das Potential zu mehr habe als das, womit er sich zufriedengebe. Die Eltern V12 strebten für ihren Sohn den Aufstieg in die Abteilung A an und warnten ihn namentlich in den zentralen übertrittsbezogenen Episoden M134 und M147 vor einem Lockerlassen:

«[Wir haben] die Wichtigkeit [immer wieder besprochen], dass man sich- einfach versucht, sein Potential zu nutzen. Wir haben jetzt mal gesagt: 'Jetzt bist du in dieser Sek B eingestuft. Mathe und Französisch in der zweiten Stufe, von 1-3.' Dass sein Ziel jetzt sein sollte, dass er dort versucht, nicht einfach zu verharren oder zu sinken, sondern wirklich sich Mühe gibt und die Zeit möglichst optimal nutzt. Weil später irgendwann, das Spektrum der Möglichkeiten wird einfach weiter, je mehr er da-» (M147)

In seinen Kontrollregulationen bescheinigte der Vater V12 - wie dies mit der Ausnahme der Mutter Z12 alle Eltern dieser Gruppe taten (vgl. Tabelle 7.16) - seinem Sohn eine eher tiefe Kontrolle (2) der Übertrittsituation: Fast durchgängig argumentierte er gegenüber K14 mit dessen stabil ungünstigem Handeln oder mit dessen variabel ungünstigem Handeln (vgl. Tabelle 9.4). Die beiden Argumente der Episoden F067 und F071, welche dispositionale Merkmale von K14 benennen (du bist ein Minimalist, was Leistungsziele betrifft und du bist ein Minimalist, was den Einsatz bei Hausaufgaben betrifft), bringen zum Ausdruck, dass V12 grundsätzlich die Einstellung seines Sohnes gegenüber Schule und Lernen missbilligte und dies an den vielen Aspekten des Handelns bei Hausaufgaben festmachte, die er in den 
einzelnen Episoden thematisierte (vgl. F070, F071, F072, F073, F075, F076). Bezogen auf den Übertritt sind vor allem die Kontrollregulationen F068 (weil du ständig fälschlicherweise denkst, in der Abteilung B könne man sich zurücklehnen) und F069 (weil du ständig nicht bedenkst, dass die Lehrstellensuche mit einer Sek B schwieriger wird) relevant, insofern als sie Ausdruck der bereits erwähnten Sorge von V12 sein dürften, wonach sein Sohn die Bedeutung, die von der jeweils besuchten Abteilung für die Berufswahl ausgehe, nicht erkennen wolle.

Mit Blick auf den Kommunikationsmodus, mit dem er in den 34 Episoden seine wert- und kontrollbezogenen Botschaften vermittelt hat, wies V12 - wie alle Eltern dieser Gruppe einen eher hohen Grad an Diskursivität (3) und - wie alle Eltern außer der Mutter H11 - auch einen eher hohen Grad an Assertivität (3) aus (vgl. Tabelle 7.12): So finden sich in den Episoden eine Vielzahl von Dialogen mit dem Sohn K14, die in der Bauernfamilie oft beim Essen stattfanden und sich nicht selten um die Bedeutung des Übertritts in die Abteilung A drehten, für welche K14 nur geringe Aspirationen aufwies:

«Bei uns finden sehr viele Diskussionen am Tisch statt, bei den Mahlzeiten, wenn wir gegessen haben. [...] mindestens drei-, viermal am Tag sitzen wir zusammen an diesem Tisch. Oder am Abend, wenn es darum gegangen ist, in seinem Zimmer, beim Lernen, beim Hausaufgaben machen. Wenn er das Gefühl hatte, es reiche jetzt, das sei jetzt genug.» (M141)

Der Vater V12 und seine Frau insistierten auf der Kenntnisnahme bzw. Befolgung ihrer wertund kontrollbezogenen Appelle: So wollte V12 seinen Sohn, weil dieser eben immer noch «eher ein Minimalist» (M136) sei, beständig «ermuntern» (M136) und «motivieren» (M135, M137, M139). Ebenso fand er, dass man K14 «schon ein wenig Druck oder [...] Ultimaten setzen» müsse (M135). Auch «überwachen» sei nötig:

«Wenn man ihm zu viele Freiheiten lässt, dann ist es eben genau das. Er macht's in den letzten fünf Minuten und so. Wir probieren [...] immer, ihn möglichst auf eine gerechte Art, ihn immer wieder zu motivieren oder sanften Druck auszuüben, dass er es wirklich macht.» (M135)

Der eher hohe Grad an emotionaler Zuwendung (3), den alle Eltern dieser Gruppe nach Erfolgen oder Misserfolgen ihres Kindes bei Mathematikprüfungen an den Tag legen, zeigte sich bei V12 im Misserfolgsfall darin, dass er mit seinem Sohn nicht schimpfte, sondern ihn in solchen Situationen zu ermutigen suchte und dessen selbstwertdienliche Erklärungen stehen ließ:

«Ich probiere, wenn ich es nicht vergesse, bis zum nächsten Mal, probiere ich natürlich schon darauf-, oder am Abend noch schnell: 'Du, K14, was habt ihr durchgenommen, hast du es denn nicht verstanden? Ging es zu schnell, oder?-' und er spricht dann schon darüber. Immer hat er nicht eine Erklärung gerade bereit. Sicher wird er nicht 
irgendwie beschimpft oder so irgendetwas, sondern wir probieren ihn zu motivieren, dass er es nächstes Mal besser macht» (vgl. Tabelle 9.5).

Deutlich wird am Beispiel von V12, dass die Eltern des Handlungstyps 1 grundsätzlich um eine zugewandte, warme Beziehung zu ihrem Kind bemüht waren, in der viel diskutiert, gefragt und gegenseitig erklärt wurde. Die Eltern schufen so jenen grundsätzlich vertrauensvollen familiären Gesprächskontext, der es den Kindern ermöglichte, ihre eigenen Sichtweisen und Befürchtungen frei zu äußern, und der es ihnen erlaubte, trotz ihrer Widerreden und dem Streit, zu dem sie die Eltern manchmal herausforderten, sich stets als Persönlichkeiten anerkannt, sicher und wertgeschätzt zu fühlen. Diese Eltern waren mit anderen Worten um jene Beziehungsqualität bemüht, die grundsätzlich «the child's openness to parental socialization» (Darling \& Steinberg, 1993, S. 493) fördert und die wenigstens langfristig die Wahrscheinlichkeit erhöht, dass die elterlichen Appelle internalisiert und befolgt werden (vgl. Abschnitte 2.3 und 5.7). Mit dem stark dialogischen Vorgehen stellten diese Eltern sodann sicher, dass die Passung ihrer Botschaften möglichst hoch war und - «tailored to the characteristics and needs of the individual» (Canning \& Harackiewicz, 2015, S. 65) - dass das Kind ihre Gründe möglichst gut nachvollziehen konnte (vgl. Abschnitte 5.6.2.3 und 5.7). Mit Blick auf die grundlegende Dimension Durchsetzungsorientierung zeigt sich ferner, dass es diesen Eltern mit der deutlichen Ausnahme von Mutter H11 (vgl. Abbildung 7.9) wichtig war, sich Gehör zu verschaffen und «schon [mit] ein wenig Druck oder [...] Ultimaten», wie es V12 in Episode M135 ausdrückte, darum besorgt waren, dass sich ihr Kind die Inhalte der wert- und kontrollbezogenen Appelle zu eigen machte.

Angesichts der hohen Beziehungsqualität und Verbindlichkeit, um die die Eltern offenkundig bemüht waren, überraschen auf den ersten Blick ihre durchschnittlichen Werte auf der grundlegenden Dimension Kindorientierung (vgl. Abbildung 7.9). Diese lassen sich allerdings dadurch erklären, dass diese Elternteile - wie es der Vater V12 mustergültig illustriert - beim Thema Übertritt, berufliche Zukunft und entsprechendem Lern- und Leistungshandeln Klartext reden und dem Kind diesbezüglich mit der Ausnahme von Mutter Z12 eine eher geringe Kontrolle (2) zuschreiben. So lautet das verdichtete evaluative Feedback des Vaters V12:

«Merke dir: Du hast die Bewältigung der Lern- und Leistungsanforderungen während der Übertrittsphase eher schlecht im Griff, weil du zu geringe Aspirationen für die in 
beruflicher Hinsicht wichtige Abteilung A aufweist und (noch) in vielerlei Hinsicht uninspiriert und unproduktiv deine Hausaufgaben erledigst.» (vgl. Tabelle 7.14).

Daneben wurden die Werte auf der grundlegenden Dimension Kindorientierung auch dadurch vermindert, dass diese Elternteile mit Ausnahme der Mutter D11 die Ausprägungen tief (1) oder eher tief (2) bei der Komponente Betonung internaler Aspekte aufweisen und mit anderen Worten eben immer wieder externale schulische Aspekte als Zweck in ihren von Zweckmäßigkeitsargumenten geprägten Wertregulationen anführten.

Diese stellen insofern das eigentliche Alleinstellungsmerkmal dieser fünf Eltern dar, als es mit E11 sowie M11 und Z32 nur noch drei weitere Elternteile aus zwei anderen Clustern gab, für die es ebenfalls typisch war, mit ZweckmäBigkeitsargumenten («weil du so etwas Erwünschtes erreichst») zu argumentieren. Wie aus den in Abschnitt 5.6.2.3 vorgestellten Befunden experimenteller Studien zur value intervention (vgl. Canning \& Harackiewicz, 2015; Harackiewicz et al., 2012; Hulleman et al., 2010; Hulleman \& Harackiewicz, 2009) geschlossen werden kann, dürften Eltern bei einer Kombination eines diskursiven Vorgehens und einer Betonung von Zweckmäßigkeit selbst bei Kindern mit geringen Kontrollüberzeugungen in der betreffenden Domäne die günstigsten Effekte hinsichtlich der Internalisierung ihrer wertbezogenen Botschaften und der Befolgung ihrer diesbezüglichen Appelle erreichen. Gehen sie dialogisch vor, gelingt es ihnen besser, die jeweiligen Hauptziele der Kinder in der betreffenden Situation zu erfahren und den von ihnen vermittelten utility value entsprechend anzupassen: «Es ist bedeutsam, dass du das tust, weil du so den von dir genannten Wunschzustand erreichst». Die Passung der dargestellten Zweckmäßigkeit, die implizit ausgedrückte Wahlfreiheit (autonomy) gekoppelt mit dem beratenden Modus des elterlichen Vorgehens («Ich rate es dir so zu machen, weil du so die von dir gewünschten Ziele (eher) erreichst, aber du kannst es auch so machen wie bisher»), dürften diskursiv angepasste positiv-valente internale oder externale Zweckmäßigkeitsargumente zu den besten Strategien der Wertvermittlung machen (vgl. Abschnitt 5.6.2.3).

Indem sie ihrem Kind nun typischerweise die aversiven Konsequenzen bzw. die Kosten (vgl. Abschnitt 5.5.1.4) vor Augen hielten, die ihm drohten, wenn es die von ihnen als bedeutsam markierten Handlungs- und Leistungsziele nicht befolge, agierten die vorliegenden fünf Elternteile allerdings vornehmlich mit negativ-valenten Zweckmäßigkeitsargumenten und setzten negative Verstärkung (vgl. Skinner, B. F., 1971, 1989) als Mittel ein (vgl. Abschnitt 5.6.2.1): «Es ist geboten, dass du so handelst, wie ich dir empfehle, weil du sonst mit den von mir genannten Kosten rechnen musst». Zwar ist der beratende Charakter der 
Zweckmäßigkeitsargumente für das Kind wohl noch immer erkennbar - die Eltern sprechen keine eigentlichen Verbote wie bei negativen Wesentlichkeitsargumenten aus («weil du das auf gar keinen Fall darfst»), allerdings ist die Wahlfreiheit bei den hier ausgesprochenen Geboten eingeschränkt, da faktisch eine Alternativlosigkeit zum Ausdruck gebracht wird und mit Druck und Angst vor den Folgen operiert wird.

Warum setzten diese fünf Elternteile, die sich mehrheitlich mit großer Reflexivität der Erziehungsaufgabe widmeten und die ansonsten in kommunikativer und emotionaler Hinsicht um jene förderlichen warmen, strukturgebenden und autonomiegewährenden Bedingungen besorgt waren, bei ihren schulbezogenen Bedeutsamkeitszuschreibungen auf Warnungen und Drohungen und brachten wenig selbstwertdienlich zum Ausdruck, dass das Kind die Lern- und Leistungsanforderungen der Übertrittsphase eher schlecht bewältige?

Die Antworten dürften sich in den Bedingungsmerkmalen finden lassen, bei denen ein signifikanter Zusammenhang mit dem Typus des Motivierungshandelns nachgewiesen werden konnte (vgl. Abschnitt 7.4.3). So zeigt sich in Tabelle 7.20, dass alle fünf Elternteile einen eher hohen (3) wert- und kontrollbezogenen Regulationsbedarf bei ihren Kindern wahrnahmen und offenbar der Meinung waren, mit ihren Appellen nicht in befriedigender Weise zu ihren Kindern durchzudringen. So meint Vater V12 in der Schlüsselstelle M154 (vgl. Anhang, Tabelle 9.1):

«[Sek B] genügt für ihn. Er will ja irgendetwas Handwerkliches lernen und das würde das ja beschreiben, hat er mir mal gesagt. Sie hatten das in der Schule auch ein wenig behandelt. Da hat er gesagt: 'Eben Sek B, das ist genau das, was man braucht, wenn man nachher Handwerker werden will.' Dann musste ich ihn dann korrigieren und sagen: 'Das reicht noch für Handwerker.' Ich will nicht den Handwerker runtermachen, aber beim anderen hätte er einfach mehr Möglichkeiten, 'selbst eben für eine Lehrstelle in einem handwerklichen Beruf hättest du bessere [Chancen].' [...] Wenn man ihm halt zum hundertsten Mal sagt, dass es gut wäre, wenn er und so weiter. Und dann ist das so sein Ding, um das Gespräch zu beenden: 'Ich bin jetzt dort und damit kann ich ja später eine Lehre [machen]'.» (M154)

Der Umstand, dass alle fünf Elternteile mindestens die Abteilung A der Sekundarschule abgeschlossen hatten (D11 und V12 besaßen sogar die Hochschulreife) und alle mit ihren Familien in einem urbanen Umfeld lebten (D11 in der stadtnahen Agglomeration, H11, H12 und V12 in der Stadt), - so lassen es die Ergebnisse der Zusammenhangsanalysen vermuten - dürfte insofern für die genannten problematischeren Facetten ihres Motivierungsstils mitverantwortlich sein, als die 
Valenz eines im Freundeskreis und der Nachbarschaft sozial akzeptablen Übertritts ihrer Kinder für diese Eltern hoch gewesen sein mag (vgl. Abschnitt 3.1.1). Tatsächlich zeigt ein Blick in die Tabelle 3.2 denn auch, dass es allen fünf Eltern dieser Gruppe zu Beginn der Erhebungszeit wichtig (2) bis sehr wichtig (3) war, dass ihr Kind zumindest nicht in die jeweils am geringsten anspruchsvolle und am wenigsten angesehene Abteilung der Sekundarschule eingeteilt wurde, die jeweils an ihrem Wohnort angeboten wurde. Für H11 und H12 sowie V12 war dies die Abteilung B, für D11 und Z12 die Abteilung C. Diese Gegebenheit mag dafür gesorgt haben, dass diese Eltern speziell in der Übertrittszeit in verstärktem Maß zu druckvolleren und potentiell Angst und Ärger erzeugenden Mitteln gegriffen haben mögen.

\subsubsection{Motivierungstyp 2: Unverbindliches, beschwichtigendes Hinweisen auf die Notwendigkeiten}

Die vier Mütter D12, M12, R12 und V11 praktizierten gegenüber ihren Kindern, den Jungen K02, K08, K13 und dem Mädchen K10 (vgl. Tabelle 4.4), das verbale Motivierungshandeln, das als «unverbindliches, beschwichtigendes Hinweisen auf die Notwendigkeiten» bezeichnet werden kann (vgl. Tabelle 7.16).

Sie handelten damit hinsichtlich der grundlegenden Dimension «Durchsetzungsorientierung» insofern anders als fast alle übrigen Elternteile (vgl. Abbildung 7.9), als ihre wert- und kontrollbezogenen Appelle eine geringe Verbindlichkeit aufwiesen: Schenkte das Kind ihren diesbezüglichen Sichtweisen kaum Beachtung oder weigerte es sich explizit, entsprechende Hinweise und Handlungsempfehlungen zu befolgen, beließen es diese Eltern typischerweise dabei. Sie insistierten kaum und waren darum bemüht, das emotionale Klima zwischen ihnen und dem Kind nicht zu stören.

Wie in Tabelle 7.16 ersichtlich ist, wiesen die vier Elternteile darüber hinaus bei einer Reihe von weiteren Stilelementen gleiche Ausprägungen auf: Typischerweise unterstrichen sie die Bedeutsamkeit der genannten Lern- und Leistungsziele mit positiv-valenten Wesentlichkeitsargumenten («weil du das einfach musst»), attestierten ihrem Kind eine eher hohe (3) Kontrolle der Übertrittssituation («Du hast die Bewältigung der Lern- und Leistungsanforderungen während dieser Phase eigentlich recht gut im Griff») und alle legten einen eher hohen Grad (3) an emotionaler Zuwendung an den Tag, was mit nüchternen, aber verständnisvollen und insbesondere mit selbstwertdienlichen Reaktionen nach Erfolgen und Misserfolgen bei Mathematikprüfungen einherging (vgl. Tabelle 6.15). Unterschiede im 
Motivierungsstil existierten unter den Eltern dahingegen bezüglich den Dimensionen Diskursivität und Betonung internaler Aspekte: Während die übrigen drei Elternteile einen eher hohen Grad (3) an Diskursivität pflegten, beschränkten sich die schulbezogenen Gespräche zwischen der Mutter D12 und ihrem Sohn K02 auf das Minimum. Und während die Mütter R12 und V12 kindbezogen eine Verpflichtung sich selbst gegenüber betonten, indem sie mit dem Begründungstyp positive internale Wesentlichkeit argumentierten («weil du das mit deinen Persönlichkeitsmerkmalen so machen musst»), agierten die beiden Mütter D12 und M12 - letztere in ausgeprägter Weise - wie fast alle übrigen Eltern der Stichprobe mit dem Begründungstyp positive externale Wesentlichkeit («weil du das als Schüler*in im Übertritt einfach musst»). Zusammengefasst lässt sich das Motivierungshandeln dieser Elternteile in der folgenden Botschaft verdichten: «Ich finde eigentlich, dass du das einfach musst, aber wenn du das nicht so siehst oder nicht willst, dann füge ich mich. Ich will dich nicht stressen und schließlich hast du die Übertrittsituation ja eigentlich recht gut im Griff.»

Die beiden Mütter R12 und V11 mit ihren identischen Merkmalsausprägungen haben sich als die am durchschnittlichsten handelnden Elternteile dieser Gruppe herausgestellt (vgl. Abschnitt 7.4.2). Im Folgenden sei das verbal-appellative Handeln der Eltern des Motivierungstyps 2 am Fallprofil der Mutter R12 nochmals illustriert, bevor es hinsichtlich seiner Potentiale und Probleme für die Motivation der Kinder diskutiert wird:

Die Mutter R12, die selber die Abteilung A der Sekundarschule besucht hat und eine Berufslehre im Dienstleistungssektor absolviert hat, war zum Zeitpunkt der Erhebung auf Stellensuche und war eine von zwei alleinerziehenden Müttern in der Stichprobe (vgl. Tabelle 4.1). Sie lebte mit der Tochter K10 und einer älteren Tochter, die wie sie in der Schweiz geboren sind, in eher unterprivilegierten Verhältnissen in der städtischen Agglomeration (vgl. Tabelle 4.3). Über den Vater und inwiefern Kontakte zu ihm bestanden, machte R12 keine Angaben (vgl. Tabelle 4.2). Die Tochter K10 wies im ersten Halbjahreszeugnis der 6. Klasse in Mathematik die Note 3.5 und in Deutsch die Note 4.5 auf (vgl. Tabelle 4.4). Am Ende der Erhebungszeit wurde sie in die Abteilung B eingeteilt, was von der Mutter begrüßt wurde. Ähnlich wie die Mutter M12, die ebenfalls den gleichen Motivierungstyp praktizierte, war R12 bereits in einer frühen Phase der Erhebungszeit, spätestens aber mit dem angesprochenen Halbjahreszeugnis, zur Überzeugung gelangt, dass ihre Tochter in der weniger anforderungsreichen Abteilung B besser aufgehoben sei (vgl. Tabelle 3.2).

Bezüglich ihrer Wertzuschreibungen wies die Mutter R12 die für die Elterngruppe charakteristische Merkmalskombination Betonung von Wesentlichkeit (2) und Betonung positiver Aspekte (3) auf. Mit der Mutter V11 teilt sie sich sodann das Merkmal der Betonung internaler Aspekte (2) (vgl. Tabelle 7.10). Die Episode M099 (vgl. Anhang, Tabelle 9.1) bildet insofern die Kernfundstelle, als sie die Inhalte anderer Episoden aufnimmt und in prägnanter Form 
wiedergibt, was R12 während der Übertrittszeit wichtig war, ihrer Tochter K10 zu signalisieren: Sich als jemanden erkennen und akzeptieren, der interesse- und fähigkeitsbezogen (erstmal) in die Abteilung B gehöre:

«[...] eben, was ich ihr gesagt habe: 'Hinauf kannst du immer und eh ja' [...] dass sie eigentlich weiß, wo ihr Platz ist und ich denke mir, sie fühlt sich doch wohler so. Anstatt jetzt [...] den Druck haben [zu müssen], weiß ich wohin eingestuft zu werden und es stimmt nicht mit ihrem Inneren überein» (M099).

Der in dieser Episode ausgedrückte Begründungstyp positive internale Wesentlichkeit widerspiegelte sich in den übrigen Wertregulationen: So setzte sie in fünf weiteren Episoden lockende bzw. die positive Norm betonende Argumente ein (vgl. M089, M100, M101, M102 und M103) und argumentierte grundsätzlich kindbezogen, indem sie in den drei Episoden M098, M100 und M103 internale, den Wissenserwerb und das emotionale Wohlbefinden betreffende Aspekte hervorhob.

Mit Blick auf die Kontrollregulationen ist die Episode F054 besonders aussagekräftig: Die Mutter meinte hier, dass es nicht der Persönlichkeit von K10 entspreche, sich mit «Sitzleder» und «geduldig mit sich selber» vertieft mit schulischen Inhalten auseinanderzusetzen:

«Weil ich denke mir, ja grundsätzlich, wenn sie sich, wenn sie sich würde,- mit was auch immer ein wenig mehr auseinandersetzen würde, dann nachher hätte sie auch mehr Erfolgserlebnisse. Aber ich denke mir, das ist einfach ihre Art».

R12 monierte denn gegenüber K10 auch, dass sie bei Schwierigkeiten mit Hausaufgaben ständig vorschnell aufgebe, statt ruhig und systematisch vorzugehen:

«Weil,- also heute haben wir Mathe miteinander gemacht und dann, wo sie es nicht gerade begriffen hat, wollte sie das Zeug hinschmeißen und ich hab gesagt: 'So funktioniert das nicht. Jetzt fangen wir wieder von vorne an und jetzt denke mal fertig.'» (F052).

Die bezüglich des häuslichen Lernens ausgedrückte tiefe Kontrolle relativierte sich allerdings, wenn sie mit ihrer Tochter auf den Übertritt zu sprechen kam. In Episode F053 bestärkte sie diesbezüglich ihre Tochter, sobald diese ihre eigene Sichtweise übernommen hatte, wonach sie bezüglich ihrer Interessen und ihrer Fähigkeiten (noch) nicht das Profil der Abteilung A erfülle (vgl. Tabelle 7.10). Die verdichtete kontrollbezogene Botschaft lautete denn auch:

«Du hast die Bewältigung der Lern- und Leistungsanforderungen während der Übertrittsphase eher gut im Griff, weil du dich zwar beständig zu wenig mit schulischen 
Inhalten auseinandersetzt und bei Schwierigkeiten vorschnell aufgibst, dies hier aber nicht so ins Gewicht fällt, weil ich es grundsätzlich richtig finde, dass du die zu dir passende - weniger anforderungsreiche - Abteilung B besuchen möchtest.» (vgl. Tabelle 7.10).

Was den Kommunikationsmodus betraf, so wies dieser die Gruppencharakteristik einer eher tiefen Assertivität (2) auf (vgl. Tabelle 7.12): Zwar brachte R12 ihre schulbezogenen Einschätzungen und Überzeugungen zum Ausdruck, insistierte aber nicht, wenn die Tochter sich weigerte oder den Appell nicht zur Kenntnis nahm: «ich kann das nicht erzwingen» (M100), «ich lasse das so stehen» und «[...] lasse sie eigentlich machen» (M103). Lediglich bezüglich des Lügens (aber nicht des schulbezogenen Inhalts der betreffenden Lüge!) zeigt R12 ein hohes Maß an Assertivität:

«Ich habe gesagt, nur so lernt sie entweder zu sagen, 'Ok, Mama, tut mir leid, ich habe es vergessen' oder was für eine Ausrede dann immer kommt. Aber ich wollte einfach nicht haben, dass sie mir sagt, sie hätte keine und geht sie [die Hausaufgaben] dann so heimlich machen. Das möchte ich nicht. Ich will,-- ja auch wenn sie mir noch sagt: 'Ich habe jetzt keinen Bock', akzeptiere ich das, aber ich akzeptiere es nicht, angelogen zu werden.» (F055)

Mit Blick auf die Diskursivität - R12 weist diesbezüglich, wie alle Elternteile der Gruppe mit Ausnahme der Mutter D12, einen eher hohen Grad (3) auf - fanden sich in der vollständigen Version der obigen Episode F055 ebenso wie in Episode M098 (vgl. Anhang, Tabelle 9.1 und Tabelle 9.3) dialogische Situationen, die detailliert mit Hilfe direkter Reden beschrieben wurden. Für ein reges Diskutieren und Verhandeln zwischen Mutter und Tochter sprach auch die Aussage von R12 in Episode M099, wonach K10 grundsätzlich alles zur Sprache bringe, was sie anders sehe als sie selbst, «aber wenn sie nicht darüber redet, ist sie eigentlich zufrieden, so wie es ist».

Der eher hohe Grad an emotionaler Zuwendung (3), den sämtliche Eltern dieser Gruppe nach Erfolgen oder Misserfolgen ihres Kindes bei Mathematikprüfungen an den Tag legten, zeigte sich bei V12 bei einem Erfolg ( $a b$ Note 4) in einem deutlichen Mitfreuen mit der Tochter: «Und dann können wir uns dann beide wirklich freuen». Sie zeichnete dann manchmal eine lachende Sonne neben die Note auf das Prüfungsblatt (vgl. Anhang, Tabelle 9.5). Bei Misserfolgen versuchte sich R12 einzufühlen und die Gründe hierfür zu erfahren. Ebenso ließ sie die selbstwertdienlichen Erklärungen ihrer Tochter stehen:

«Ja, ich, also ich frag einfach, ob sie das Ganze nicht verstanden hätte oder ob jetzt,ihr reicht es vielfach zeitlich nicht. Einfach, ja sie braucht einfach mehr Zeit und dann, wenn sie unter Zeitdruck ist, denke ich immer, kommt sie ins Hasten und macht dann noch Flüchtigkeitsfehler, darum. Aber, ich meine, ich schimpf jetzt nicht, ich lasse es 
so stehen, wie es ist, fertig. Und dann habe ich halt auch schon einen Grumpy gemacht, nicht nur eine Sonne.» (vgl. Anhang, Tabelle 9.5)

Am Beispiel von R12 wird deutlich, dass die Eltern des Handlungstyps 2 grundsätzlich um eine harmonische oder zumindest reibungsfreie Beziehung mit dem Kind bemüht waren. Außer wenn grundlegendere Werte wie Ehrlichkeit verletzt wurden, wollte man sich diese nicht trüben lassen - auch nicht durch den schulischen Alltag des Kindes und die Konflikte, die aus nicht gelingenden Hausaufgaben und misslungenen Prüfungen erwachsen. Das Alleinstellungsmerkmal dieser Gruppe, das in einer stark unterdurchschnittlichen Durchsetzungsorientierung bzw. in einer eher geringen (2) Assertivität bestand und sich bei den Eltern der anderen Clustern nur noch bei den beiden Müttern H11 und Z32 in ähnlicher Ausprägung fand (vgl. Abbildung 7.7), trägt am stärksten zum Gesamteindruck des Beschwichtigens bei: Alle vier Elternteile berichteten zumindest von vergangenen Konflikten mit ihren Kindern, die man als belastend empfand, und nannten in den Interviews Gründe dafür, warum ihnen diese momentan zu viel seien. So meint die Mutter D11 in der diesbezüglichen Schlüsselstelle M020 (vgl. Anhang, Tabelle 9.1) auf die Frage, ob es manchmal Streit bei Hausaufgaben gebe:

«Ja, eben im Moment bin ich selbst im Stress. Ich sollte auch noch lernen. Dann mag ich auch nicht mehr dahinter sein. (I: Selber Hausaufgaben?) Ja genau. Also ich sage es schon, aber ich mache nicht so einen Druck. Manchmal bringt das auch nichts, wenn er nicht will, dann will er nicht. (I: Dann lassen Sie ihn einfach?) Also von dem her, habe ich eine zu wenig autoritäre Erziehung oder so. Ja, dann lasse ich ihn eben.» (M020)

Der Mutter M12 und ihrem Mann war es wichtig, auf keinen Fall «Druck auf das Kind aus[zu]üben. Das möchten wir nicht» (M081), weil ihr Sohn K08 in diesen Monaten an der Juvenilen idiopathischen Arthritis litt, die mit gelegentlich großen Gelenkschmerzen einherging. Sie hatte ferner die Erfahrung machen müssen, dass sie bei ihrem Sohn mit Druck genau das Gegenteil des Intendierten bewirkte:

«Es brächte nichts, weil äh, K08 hat ganz schlechte Erfahrungen mit seinen Schulkollegen, bei denen die Eltern ums Verrecken wollen, dass diese Kinder in diese Sek gehen und kaum Sek A-Schüler sind, noch an eine Gymnasiumsprüfung müssen. Also, das ist grauenhaft. Also, grauenhaft. Und das machen wir nicht. Ich merke, je mehr wir ihn in Ruhe lassen, desto mehr leistet er. Er ist so einer. Wenn du beginnst zu drücken, dann macht er wie den Schirm zu. Das ödet ihn dann an und dann hat er keine Freude mehr. Ja.» (M082) 
Insistierte sie auf ihren Appellen, so ihre Erfahrung, hätte er sich schlicht geweigert:

«[...] ich [habe] ihm gesagt [...] beim letzten Zeugnis: 'Du musst dich ein wenig in den Po kneifen, also, du musst dir etwas mehr Mühe geben.' Aber ich glaube sowieso nicht, dass er das macht (lacht). Eigentlich glaube ich nicht, dass er das macht, denn er ist immer gleich, er- Ich kann es dir nicht sagen.» (M085)

Die Mutter V11 war dahingegen zum Erhebungszeitpunkt nach eigenen Angaben stark mit der schulbezogenen Unterstützung der kleinen Schwester ihres Sohns K13 beschäftigt, mit dem sie in der Vergangenheit große schulbezogene Konflikte ausgetragen hatte, bis er eine Medikation für seine ADS-Problematik erhielt. Nun hatte sie die Unterstützung ihres Sohnes «ein stückweit [...] delegiert» (M129) und ihn für professionelle Nachhilfe und schulische Förderstunden angemeldet: «K13 habe ich wie so ein wenig gehen lassen. Gehen lassen nicht im Sinn, dass ich nicht schaue. Aber so, dass ich ihn eigentlich machen lasse» (M128). Sie drückte über alle Episoden hinweg Aufmerksamkeit, aber auch etwas Distanz gegenüber der Situation ihres Sohnes aus, was der gelegentlichen Überforderung mit der familiären Situation geschuldet sein mochte. In ihren lernbezogenen Wertund Kontrollregulationen zeigte sich die Mutter V11 wenig insistierend: «Ich sage ihm schon: 'Jetzt solltest du nicht abhängen.' Aber [...] ich sage es immer nur halbherzig. Ich verstehe ihn» (M126). Allerdings markierte sie anders als die übrigen drei Elternteile eine große Verbindlichkeit, wenn es um den Übertritt ging:

«Und ich habe ihm halt immer gesagt: 'Schau, wenn du in die Sek B kommst, dann gehst du in eine Privatschule (lacht). Ich lasse dich nicht in die Öffentliche [Sekundarschule gehen].' Auch ein wenig das Gemeine von mir. Das habe ich ihm in der 5. Klasse sicher mehr als einmal gesagt.» (M132)

Die ansonsten zu Tage tretende Unverbindlichkeit und das Beschwichtigen der vier Eltern war, wie im Fallprofil von R12 illustriert, ferner durch ein zwar selbstwertdienliches, die wahrgenommenen Probleme im Lernen aber oft nicht klar benennendes evaluatives Feedback gekennzeichnet. Unter Vernachlässigung ihrer Rolle als «interpreters of reality» (Jacobs \& Eccles, 2000, S. 426) nahmen sich diese Eltern auch hier zugunsten der Konfliktlosigkeit eher zurück. Bezüglich des Übertritts attestierten sie ihrem Kind, dass es diesen im Griff habe - einerseits, weil sich die Noten in den Monaten tatsächlich verbessert hatten (bei den Söhnen von D11 und V11), anderseits, weil die Eltern ihrem Kind bedeutet hatten, dass sie auf Druck verzichten würden und ihnen auch die Abteilung $\mathrm{B}$ genüge 
(bei M12 und R12). In diesem Licht reiht sich sodann auch das Argumentieren mit positiver Wesentlichkeit bei Wertregulationen («Mach es, weil du das einfach musst») in den ausweichenden Stil ein: Auf Notwendigkeiten verweisen überträgt die Verantwortung insofern dem Kind, als man selber nicht weiter zu erklären und zu beraten braucht, was Zeit benötigt und potentiell Widerspruch auslöst.

In motivationaler und lerntheoretischer Hinsicht ist der Handlungstyp 2 denn auch als problematisch zu kennzeichnen: Einerseits begegnen diese Eltern ihrem Kind mit Wärme, agieren betont selbstwertdienlich und sind mit Ausnahme von D11 in regem Dialog mit ihm, indem sie Interesse an den schulbezogenen Sichtweisen und Überzeugungen der Kinder zeigen (vgl. Tabelle 7.16). Sie stellen damit also eigentlich mehrheitlich gute Bedingungen für die Internalisierung ihrer wert- und kontrollbezogenen Appelle her (vgl. Abschnitt 5.7). Andererseits dürften sie durch das Relativieren ihrer diesbezüglichen Botschaften («Eigentlich finde ich, du müsstest ..., aber wenn du es anders siehst, dann...»), durch ihren Verzicht auf angepasste Zweckmäßigkeitsargumente (vgl. Abschnitt 8.2.1) sowie den Verzicht auf evaluative Feedbacks, die die erkannten Unzulänglichkeiten im Handeln klar benennen, (auch) in den Augen ihrer Kinder ihre Rolle als Strukturgebende nur unzureichend wahrnehmen (vgl. Skinner, E. A. et al., 2009, S. 186). Diese Eltern gewährten ihren Kindern ein relativ hohes $\mathrm{Ma} ß$ an Entscheidungsfreiheit (authonomy), ließen sie so weit wie möglich ihre eigenen Präferenzen wahrnehmen (vgl. Tabelle 2.1), aber vermieden es weitgehend, sperrig zu sein und von ihnen entwicklungsförderliche Zumutungen und Herausforderungen zu fordern, wenn diese entsprechende abschlägige Signale gaben. Zumindest was die schulische Domäne betraf, dürften die Wert- und Kontrollzuschreibungen der vier Eltern aus der Perspektive der Kinder nur begrenzt maßgeblich gewesen sein und die Eltern dürften diesbezüglich über wenig Autorität verfügt haben. Fehlen «modest amounts of power assertation», so lässt sich mit Grusec (2011, S. 257) schließen, so fehlt auf Seiten der Kinder «the motivation that focuses [their] attention and encourages them to listen and to engage in the learning process».

\subsubsection{Motivierungstyp 3: Ungeschminktes und schonungsloses Vermitteln der negativen leistungsbezogenen Einschätzung}

Die Gruppe von drei Elternteilen, die den Motivierungstyp «Ungeschminktes und schonungsloses Vermitteln der negativen leistungsbezogenen Einschätzung während der Übertrittszeit» praktiziert hatten, setzte sich aus den Müttern E11, und 
Z32 sowie aus dem Vater Z22 zusammen (vgl. Tabelle 7.16). Ihre Kinder waren der Junge K03 sowie die Mädchen K18 und K20 (vgl. Tabelle 4.4).

Das Charakteristische am Motivierungsstil dieser Elternteile bestand darin, dass sie bei der grundlegenden Dimension «Kindorientierung» so ausgeprägt unterdurchschnittliche Werte aufwiesen wie sonst keine anderen Eltern der Stichprobe (vgl. Abbildung 7.9). Bezüglich der Stilkomponenten Diskursivität, Zugeschriebene Kontrolle, Emotionale Zuwendung und Betonung internaler Aspekte zeigten die drei Elternteile denn auch durchgängig die Ausprägung tief (1) oder eher tief (2) (vgl. Tabelle 7.16). Hinsichtlich der übrigen Komponenten Betonung von Wesentlichkeit, Betonung positiver Aspekte und Assertivität, die eher prägend sind für die Dimensionen Normorientierung und Durchsetzungsorientierung (vgl. Tabelle 7.15), unterschieden sich die Elternteile dahingegen in ihren Ausprägungen (vgl. Tabelle 7.16).

Gemessen an seinen Merkmalsausprägungen ist der Vater Z22 insgesamt der typischste Vertreter dieses Motivierungstyps (vgl. Abschnitt 7.4.2). Wie in den vorangegangenen Kapiteln soll im Folgenden das verbal-appellative Handeln der Eltern des Motivierungstyps 3 am Beispiel seines Fallprofils eingehender beschrieben und dann hinsichtlich möglicher Effekte auf die Lern- und Leistungsmotivation der Kinder diskutiert werden:

Der Vater Z22, der selber die Abteilung B der Sekundarschule besucht und eine Lehre in einem handwerklichen Beruf absolviert hat, ist verheiratet (vgl. Tabelle 4.1) und lebte zum Zeitpunkt der Erhebung mit seiner Frau, mit der Tochter K18 sowie einem älteren Sohn in eher privilegierten Verhältnissen in einer ländlichen Gemeinde des Kantons Zürich. Er und die übrigen Familienmitglieder sind in der Schweiz geboren und aufgewachsen (vgl. Tabelle 4.3). Die Tochter K18 wies im ersten Halbjahreszeugnis der 6. Klasse in Mathematik und in Deutsch die Note 4.5 auf (vgl. Tabelle 4.4). Am Ende der Erhebungszeit wurde sie in die Abteilung A eingeteilt, was den Eltern sehr wichtig gewesen war (vgl. Tabelle 3.2).

Bezüglich seiner Wertzuschreibungen wies der Vater Z22 die Merkmalskombination Betonung von Wesentlichkeit (3), Betonung positiver Aspekte (3) sowie Betonung externaler Aspekte (1) auf. Er teilte sich diese Merkmalskonfiguration mit der Mutter Z32, nicht aber mit der Mutter E11, die zwar ebenfalls eher externale Aspekte (2) betonte, sonst aber wie die Eltern der Gruppe 1 vornehmlich mit negativen Zweckmäßigkeitsargumenten agierte (vgl. Tabelle 7.10). Hinsichtlich des gruppenspezifischen Charakteristikums einer geringen Kindorientierung ist namentlich die geringe Betonung internaler Aspekte relevant:

Die typische Begründung für die Bedeutsamkeit eines schulbezogenen Lern- oder Leistungsziels bestand bei Z22 denn auch in der Botschaft, «weil es deine Pflicht ist und es von deiner sozialen Umwelt so erwartet wird». Die Tochter K18 wurde dabei in ihrer Rolle als Familienmitglied angesprochen (weil sich das für dich als unser Kind so gehört), wobei u. a. folgende Aspekte als bedeutsam markiert wurden: konzentrieren, wenn man dir hilft! (M175), mit mir 
üben, bist es sitzt! (M176), den Schulstoff auch wirklich verstehen! (M180), immer Respekt gegenüber den Lehrkräften zeigen! (M182). In den weiteren Wesentlichkeitsargumenten mit externalem Lokus thematisierte Z22 den Übertritt und wies seine Tochter auf ihre Rolle als Anwärterin bzw. zukünftige Schülerin der Abteilung A hin (weil du das als angehende SekA-Schülerin einfach musst): Defizite in Mathematik und Französisch aufarbeiten und mit mir in den Ferien «rückwärts und vorwärts» üben - «das muss sitzen!» (M178) sowie gute Noten machen! («'Du weißt, die Noten müssen stimmen.' Wenn die Noten nicht stimmen, muss ich schwer diskutieren», M183, vgl. Anhang, Tabelle 9.1). Auch in M177, der einzigen Episode mit Zweckmäßigkeitsargument, warnte er seine Tochter K18 davor, es auch in der letzten Phase vor dem Übertritt zu locker zu nehmen, und forderte sie auf, in den letzten Wochen der 6. Klasse und in den Sommerferien (vgl. M178) «die Themen aufzuarbeiten, die im A vertieft werden oder nochmals kommen [...] Weil brutal Material und eine rechte Datenflut auf sie zukommt, die sie verarbeiten muss» (M177).

Verdichtet lautete die typische Botschaft von Z22, die gruppentypisch externale Aspekte, namentlich den Übertritt, betonte: «Es ist bedeutsam, dass du jetzt (während der Übertrittsphase) so handelst, weil du das als unsere Tochter und als angehende Schülerin der anspruchsvollen Abteilung A einfach unbedingt musst!» (vgl. Tabelle 7.14).

Bei der Komponente Zuschreibung von Kontrolle bezüglich der Lern- und Leistungsanforderungen während der Übertrittszeit wies Z22, wie alle Eltern dieser Gruppe, die Ausprägung eher tief (2) auf. Wie in Abschnitt 7.4.1 erläutert, stellt die Komponente die zweitwichtigste Facette der Grunddimension Kindorientierung dar - ein Umstand, der vermutlich der Tatsache geschuldet ist, dass Kontrollzuschreibungen unterschiedlich selbstwertdienlich gestaltet sein können:

Im Kontext seines Bemühens, beim gemeinsamen Bearbeiten von Hausaufgaben oder bei gemeinsamen Repetitionsrunden während der Schulferien ein tieferes Verständnis mathematischer Inhalte und Zusammenhänge bei seiner Tochter zu fördern, attestierte der Vater seiner Tochter in Episode F092 (vgl. Anhang, Tabelle 9.3) eine diesbezüglich geringe Kontrolle, was bei K18 zu Frustration und bei ihm wiederum zu heftigen Reaktionen führte:

«[...] Also Thema ist es schon sicher mal vor den Prüfungen, wenn ich erfahre, dass sie eine Prüfung hat. Dass wir mal reinschauen. Bei den Hausaufgaben, wenn sie es nicht versteht, obwohl sie dort echt Mühe hat, wenn ich draufschaue und so, dann wird sie teilweise missmutig. Dass sie fast anfängt zu weinen, wenn ich dort ein wenig bohren möchte, schauen, ob sie es verstanden hat. Dann macht sie vielfach zu, dann muss ich wirklich sagen: 'Jetzt setz dich hin und jetzt wird das gemacht, fertig.'» (F092)

K18 mied offenbar die Lernunterstützung ihres Vaters («sie geht mehr zur Mutter», F092), was von ihm wiederum zusammen mit der manchmal fehlenden Verstehensorientierung beim Lernen anlässlich der Besprechung von misslungenen Prüfungen moniert wurde: 
«'Wieso kommst du nicht? Was ist das Problem? Wie ich schon gesagt habe, du musst wissen, wieso. Du kannst nicht nur Hausaufgaben machen und erledigen. Du arbeitest für dich und nicht für die Lehrerin. Die Hausaufgaben sind eigentlich da, damit du das Thema vertiefen kannst und dass du es schlussendlich begriffen hast'» (F093).

Die meist auf das stabil ungenügende Handeln des Kindes zeigenden evaluativen Feedbacks ließen sich folgendermaßen verdichten: «Merke dir: Du hast die Bewältigung der Lern- und Leistungsanforderungen während der Übertrittsphase eher schlecht im Griff, weil du beim Lernen meist noch zu wenig verstehensorientiert vorgehst und mich nicht selbständig aufsuchst, wenn du es nicht verstehst.»

Die Stilkomponente Diskursivität, bei der alle Eltern des Motivierungstyps 3 die Ausprägung eher tief (2) aufwiesen, stellt die wichtigste Facette der grundlegenden Dimension Kindorientierung dar (vgl. Tabelle 7.15). Die obigen Ausschnitte illustrieren, dass zumindest die lernund leistungsbezogene Kommunikation zwischen ihm und seiner Tochter unidirektional und von seiner Seite wenig sensibel und adaptiv war. In Gesprächen über Hausaufgaben und Prüfungsergebnisse (M175/F092, M176, M177, M178) wurde sichtbar, dass die Tochter «echt Mühe hat, wenn ich draufschaue», «missmutig» wird und «fast anfängt zu weinen, wenn ich dort ein wenig bohren möchte» und sich schließlich zurückzog («dann macht sie vielfach zu», M175) oder es aber vermied, ihren Vater aufzusuchen, obwohl sie eigentlich Bedarf nach Hilfe hatte («sie geht mehr zur Mutter», M175).

Wie die Mutter E11, aber anders als die Mutter Z32 - die diesbezüglich ähnlich handelte wie die Eltern des Motivierungstyps 2 -, wies Z22 einen überdurchschnittlichen Wert bei der grundlegenden Dimension Durchsetzungsorientierung auf (vgl. Abbildung 7.7). Die Gründe für das Meideverhalten von K18 dürften in der Art und Weise gelegen haben, wie er seine Tochter zu überzeugen suchte und wie er reagierte, wenn sie seinen Erwartungen nicht entsprach. In solchen Situationen setzte Z22 mitunter Zwang ein, was besonders in Episode M176 deutlich wurde, in der er beschrieb, dass er seine Tochter dazu drängen wollte, während den Sommerferien den Basisstoff in Mathematik gemeinsam mit ihm aufzuarbeiten:

«Mathe können sie mich alles fragen, das mache ich auch gerne. Von einer anderen Seite her erklären, dass es klar wird. Auf die eine Seite freue ich mich, denn beim Junior, der ein Jahr weiter ist, habe ich jetzt die Themen mitbekommen [...]. Deshalb müssen gewisse Sachen knallhart sitzen. Die müssen dort loslegen. Ich weiß jetzt schon, sie wird weinen. Die wird weinen. Ja am Anfang, weil ein gewisser Druck von mir kommt. Da wird sie hundertprozentig weinen und ich hoffe, dass sie das einsieht, dass das sitzen muss. Wenn sie das einsieht, dann ist das kein Thema mehr. Wenn die Einsicht da ist, dann geht es los bei ihr. Weil sie ein Typ ist, der brutal, gnadenlos dranbleibt. Dass sie das noch hinbringt? Wie es so ist, man kann keinen Menschen motivieren, obwohl immer alle reden. Motivieren, motiviere ihn! Das kann kein Mensch. Man kann nur Anreize bieten, um einen Menschen zu optim... äh motivieren. Alle reden immer, du musst ihn motivieren, das sehen viele nicht ein. Aber der Anreiz, der einen Menschen 
motiviert, das ist doch das, was es braucht. Und an dem bin ich noch am Suchen.» (M176)

Zwang zur Aufarbeitung der Fehler wurde sodann auch bei ungenügenden Prüfungsergebnissen erkennbar: Z22 blieb in einem solchen Fall besonders beharrlich dran und beließ es nicht bei Aufforderungen und evaluativen Feedbacks, sondern setzte auf enge Begleitung: «Wenn es ungenügend wird, dann bin ich da, dann suche ich Aufgaben im Internet zum Thema oder habe schon selber Blätter gemacht» (M177).

Mit Blick auf die Stilkomponente emotionale Zuwendung, einer weiteren Facette der Dimension Kindorientierung (vgl. Tabelle 7.15) zeigte sich denn in solchen prüfungsbezogenen Gesprächen auch, dass Z22 Fehler mit geringer Rücksicht auf den emotionalen Zustand seiner Tochter thematisierte, kaum Trost spendete und ihr Vorwürfe machte. Diese meldete sich daher bei Misserfolgen nicht von sich aus bei ihrem Vater und wurde in solchen Situationen von der Mutter gestützt:

«[...] Also schon klar, auch bei schlechten Noten bin ich nicht der, der sie streichelt. Überhaupt nicht: 'Oh, du Arme, einen schlechten Tag gehabt?' und so, nein gar nicht. Das wird dann eher von der Frau gemacht.» (vgl. Anhang, Tabelle 9.5).

Auch bei erfolgreichen Mathematikprüfungen freute sich Z22 nicht vorbehaltlos mit seiner Tochter, sondern suchte nach den Fehlern und betonte diese vor K18:

«Bei einer guten Note? [...] Klar, /smilen/oder? (Lachen) 'Gut gemacht.' Obwohl, gut gemacht, ich schaue schon noch die Fehler an, wenn ich die Prüfung sehe. Es ist, wissen Sie, es ist schwierig. Ich habe teilweise das Gefühl, dass wenn es nicht so gut ist, dass meine Frau sie leicht in Schutz nimmt. Meine Frau kennt mich auch, sie weiß, dass ich leistungsorientiert bin und auftische (klopft auf den Tisch), was nicht gut ist. Da nehme ich keine Rücksicht. Das soll sie spüren» (vgl. Anhang, Tabelle 9.5).

Es ist das von Z22 erwähnte «Auftischen», das den von einer geringen Kindorientierung geprägten Motivierungsstil dieser Eltern gut zusammenfasst: In Wertregulationen bringen sie die äußeren Realitäten in Form von Erwartungen, Normen, Pflichten und Anforderungen vor, in den Kontrollregulationen achten sie vor allem auf die Kommunikation einer deutlichen und realistischen Beurteilung des betreffenden Sachverhalts («Merke dir: Du hast dies eher schlecht im Griff»), in Prüfungsbesprechungen verhehlten sie auch bei Ergebnissen, die das Kind als Erfolg einschätzte nicht, dass sie eigentlich höhere Erwartungen hätten. Das seltene kindbezogene Argumentieren («weil du es für dich machen musst»bzw. «weil du so persönliche Ziele erreichen kannst»), die geringe Selbstwirksamkeits- 
und Selbstwertdienlichkeit ihrer evaluativen Feedbacks sowie die Außerachtlassung emotionaler Bedürfnisse des Kindes im Umgang mit Leistungsergebnissen widerspiegelt sich schließlich in der geringen Dialogizität ihrer Wert- und Kontrollregulationen: Die drei Elternteile berichten kaum von Situationen, in denen ihre Kinder ihre Sichtweisen argumentativ vorbrachten oder in denen diese von ihnen aktiv danach gefragt worden wären, um eine möglichst große Passung ihrer Botschaften mit deren eigenen Einschätzungen herzustellen. Stattdessen berichteten auch die beiden Mütter von der gleichen Erfahrung wie Z22, wonach sich ihre Kinder ihnen entzögen und ihre schulbezogene Kommunikation mit ihnen auf das Minimum beschränkten. Wie die Zusammenhangsanalysen zeigten, nahmen denn auch alle Elternteile einen hohen Regulationsbedarf (3) bei ihren Kindern wahr, hatten also das Gefühl, mit ihren Botschaften nicht zu ihnen durchzudringen (vgl. Tabelle 7.20). Selbst wenn Persönlichkeitsmerkmale der Kinder ihren Anteil daran haben mochten, so dürfte die Heftigkeit, mit der die Mutter E11 auf das Nichtbefolgen ihrer Appelle reagiert hatte - z. B. «Das ertrage ich dann nicht» (M029), «jetzt Herrgott nochmal» (F018), «Larifarizeug» (M031), «da war ich schon mehrmals sauer» (F017) -, der Zwang, den Z22 auszuüben bereit war, sowie der resignative Ton und die geringe Durchsetzungsorientierung, die in den Schilderungen der Mutter Z32 zum Ausdruck kamen (vgl. M191, M194, F100), diese Tendenzen eher verstärkt als abgeschwächt haben.

Der Motivierungsstil des Handlungstyps 3 ist aus motivations- und emotionspsychologischer Sicht denn auch klar als problematisch zu taxieren. Mit ihrem unidirektionalen Kommunikationsverhalten und der damit einhergehenden fehlenden Diagnose dürfte es diesen Eltern schlecht gelungen sein, ihre wert- und kontrollbezogenen Botschaften so zu formulieren, dass sie eine möglichst gute Passung zu den bestehenden wertbezogenen Einschätzungen und Überzeugungen sowie zum jeweiligen Bedarf an selbstwirksamkeits- und selbstwertförderlichen Anmerkungen und Tönungen der Botschaften auf Seiten ihrer Kinder herstellen konnten. Die Sprachlosigkeit und Tränen, das fehlende Vertrauen und die Angst, welche in den Episoden der drei Elternteile anklingen, dürften aber auch stark dem Umstand geschuldet sein, dass diese Eltern gerade in den kritischen Momenten von Gesprächen über Leistungsergebnisse, in denen der Lernfortschritt der Kinder und deren Leistungsfähigkeit besonders im Brennpunkt und zur Disposition stehen, ihre erhöhten Erwartungen zum Ausdruck brachten und mit wenig Schonung auf das Ungenügen zeigten. Laut den Zusammenhangsanalysen mit einem eher tiefen Schulabschluss sowie mit einem ländlichen Milieu assoziiert (vgl. Tabelle 7.20), beinhaltet der Motivierungstyp 3 im Kern Verhaltensformen, die von Skinner und Kolleg*innen (2009, S. 186) der rejection zugeordnet werden 
(vgl. Abschnitt 2.2.2.4, insb. Tabelle 2.1). Es handelt sich dabei um Verhaltensformen, denen die bisherige Forschung zur Motivationsförderung klar einen hinderlichen Effekt auf die Internalisierung elterlicher schulbezogener Werte und Erwartungen bescheinigt (u. a. Grolnick \& Ryan, 1989; Grolnick et al., 1991; Simpkins et al., 2006; zsf. Wigfield, Eccles, et al., 2015, S. 25).

\subsubsection{Motivierungstyp 4: Standfestes, diskursives Überzeugenwollen mittels gewinnender Argumente}

Die Gruppe von Elternteilen, die während der Übertrittszeit den Motivierungstyp 4 praktiziert hatte, setzte sich aus den fünf Müttern E12, R11, S11, Z11, und Z31 sowie dem Vater M11 zusammen (vgl. Tabelle 7.16). Ihre Kinder waren die beiden Mädchen K04 und K15 und die vier Jungen K07, K11, K13 und K19 (vgl. Tabelle 4.4).

Das Charakteristische am Motivierungsstil dieser Elternteile bestand darin, dass sie bei den drei Komponenten, welche jede für sich jeweils eine der drei grundlegenden Dimensionen Normorientierung, Kindorientierung und Durchsetzungsorientierung am stärksten prägte (vgl. Tabelle 7.15), die Ausprägung eher hoch (3) aufwiesen.

Die Stilkomponente Betonung positiver Aspekte bildete die prägendste Facette der Dimension Normorientierung. Die Ausprägung eher hoch (3) ging mit einer Bedeutsamkeitsvermittlung einher, in der die sechs Eltern das Kind zu überzeugen suchten, indem sie ihm mit positiv-valenten Argumenten das gesellschaftlich Erwartete und somit Anerkannte und Problemlose (positiv externale Wesentlichkeit: E12, R11, S11), das persönlich Gebotene (positiv internale Wesentlichkeit: Z11) oder ein lohnender gesellschaftlicher Zweck (positiv externale Zweckmäßigkeit: M11, Z31) vor Augen hielten (vgl. Abschnitt 5.6.2.1). Die sechs Elternteile versuchten mit anderen Worten, ihre Kinder mittels gewinnender Argumente zu überzeugen.

Die Komponente Diskursivität war die prägendste Facette der Dimension Kindorientierung. Die sechs Elternteile zeigten sich generell bestrebt, ihre Bedeutsamkeitseinschätzungen und evaluativen Feedbacks zu begründen, die Sichtweise des Kindes aktiv zu erfragen, auf seine Einwände einzugehen und so adaptiv die Passung ihrer wert- und kontrollbezogenen Botschaft mit den Einschätzungen und Überzeugungen der Kinder sicherzustellen (vgl. Tabelle 7.12).

Die Dimension Durchsetzungsorientierung, bei der die sechs Elternteile überdurchschnittliche Werte auswiesen, wurde klar durch die Facette Assertivität geprägt. Die sechs Elternteile koppelten demnach ihr diskursives Vorgehen mit 
dem Insistieren auf einer Beachtung und Befolgung ihrer Appelle. Mit dem festen Ziel, ihr Kind zu überzeugen, ließen diese Eltern nicht locker, zeigten sich standfest und wiederholten ihre Botschaften bei Bedarf (vgl. Tabelle 7.14).

Gemessen an den Ausprägungen, welche die Mutter S11 auf den sieben Stilkomponenten aufwies, war sie insgesamt die typischste Vertreterin dieser Gruppe (vgl. Abschnitt 7.4.2). An ihrem Fallprofil sollen die Kennzeichen des Handelns des Motivierungstyps 4 im Folgenden wieder eingehender illustriert und diskutiert werden:

Die Mutter S11 ist verheiratet und lebte zum Zeitpunkt der Erhebung mit ihrem aus einem anderen europäischen Land stammenden Mann, dem Sohn K11 und einem weiteren jüngeren Sohn in privilegierten Verhältnissen in einer ländlichen Gemeinde des Kantons Zürich. Sie hat die Abteilung B der Sekundarschule besucht und eine Lehre im Dienstleistungssektor absolviert, in dem sie auch zum Zeitpunkt der Erhebung noch tätig war (vgl. Tabelle 4.1). S11 und ihre Kinder sind im Gegensatz zu ihrem Mann in der Schweiz geboren und aufgewachsen (vgl. Tabelle 4.3). Ihr Sohn K11 wies im ersten Halbjahreszeugnis der 6. Klasse in Mathematik und in Deutsch die Note 4.5 auf (vgl. Tabelle 4.4). Am Ende der Erhebungszeit wurde er in die Abteilung A eingeteilt, was der Mutter, vor allem aber dem Vater, der ein Universitätsstudium in seinem Herkunftsland absolviert hat, sehr wichtig gewesen war (vgl. Tabelle 3.2).

Bezüglich ihrer Wertzuschreibungen wies die Mutter S11 die Merkmalskombination Betonung von Wesentlichkeit (3), Betonung positiver Aspekte (3) sowie Betonung externaler Aspekte (1) auf. Während sich bezüglich der beiden letzteren Komponenten übereinstimmende Ausprägungen zwischen allen Mitgliedern dieser Gruppe fanden - die übrigen hatten allerdings etwas weniger eindeutig (Ausprägung 2) mit externalen Aspekten argumentiert als S11 (Ausprägung 1) -, agierten der Vater M11 und die Mutter Z31, anders als S11 und die übrigen Elternteile, typischerweise mit dem Aufgabenwert Zweckmäßigkeit (vgl. Tabelle 7.16).

Die Mutter S11 argumentierte dahingegen meist mit Wesentlichkeit, wobei sie gegenüber ihrem Sohn K11 fast durchgängig Rollenerwartungen zum Ausdruck brachte (vgl. Anhang, Tabelle 9.2). S11 und ihr Mann waren zu Beginn der Untersuchungszeit von der Klassenlehrkraft L05 mit dem Bescheid überrascht worden, dass ihr Sohn Gefahr laufe, in die Abteilung B eingeteilt zu werden (vgl. M106). Ab diesem Zeitpunkt sei der Übertritt, so S11, «allgemein, [...] also vor und nach jeder Prüfung» (M106) zum zentralen Thema geworden:

«Ja, erstens [haben wir immer wieder besprochen], dass es für ihn schöner wäre, wenn er mit seinen Freunden zusammen wäre dann nachher in der Schule, weil ja alle ins A kommen, und einfach, dass es halt wichtig ist, dass er mal dort beginnt, auch wenn er nachher ins B kommt oder was auch immer, aber dass es wichtig ist, dass er ins A kommt. Es ist ein extremer Druck, den wir auch weitergegeben haben.» 
In diesem Kontext brachten ihre externalen Wesentlichkeitsargumente Pflichten und Erwartungen zum Ausdruck, die an ihren Sohn in seiner Rolle als Schüler in der Statuspassage gestellt wurden: weil du den Übertritt in die Abteilung A auf keinen Fall aufs Spiel setzen darfst bzw. weil du das in der Übertrittsphase einfach musst! (M106, M115), weil du das als Schüler einfach musst! (M107, M110) sowie weil du das als Sek-A-Anwärter einfach musst!

Bezüglich der Komponente Kontrollzuschreibung zeigte sich, dass die Mutter S11 mit einer Reihe positiv-valenter Argumente, die stabile Bedingungen beim Kind oder dessen stabiles Handeln thematisierten, trotz des Drucks, den sie und ihr Mann erzeugten, immer wieder darum bemüht war, ihrem Sohn ihre Zuversicht und ihr Vertrauen auszudrücken, wonach er die Lern- und Leistungsanforderungen der Übertrittsphase meistern werde: So attestiert sie ihrem Sohn, dass er gereift sei und den Ernst der Lage erfasst habe, dass er anders als früher nun meist konzentriert an seinen Hausaufgaben arbeite «Jetzt ist es wirklich mehr aufgabenbezogen und vorher musste man mehr schauen, dass er's überhaupt macht und dass er nicht irgendwie immer wieder beginnt zu spielen daneben» (F056). Ebenso habe er nun erkannt, dass er nicht alles selber können und bewältigen müsse, sondern bei Hausaufgabenproblemen aktiv andere um Hilfe bitten könne (F058). Nebst diesen Zuschreibungen hoher Kontrolle merkte S11 gegenüber K11 aber auch kritisch an, dass er hin und wieder noch immer nicht zwischen Arbeits-, Freizeit- und Ruhephasen unterscheiden könne und in dieser Beziehung von ihr manchmal entsprechend reguliert werden müsse (F057, F059, vgl. Anhang, Tabelle 9.4).

Bezüglich der Komponente Diskursivität, welche die wichtigste Facette der grundlegenden Dimension Kindorientierung darstellt, wies S11 die gruppencharakteristische eher hohe (3) Ausprägung auf: In den Episoden F058, M110 und M112 illustrierte die Mutter S11 Dialoge zwischen ihr und ihrem Sohn. Dieser brachte sich aktiv ein, fragte nach, haderte und beklagte sich über die Hausaufgaben, deren Sinn er nicht verstand, und er wehrte sich gegen falsche Einschätzungen. Die Mutter S11 ging darauf ein und argumentierte. Ebenso berichtete sie von «Diskussionen» (M110) zwischen ihr, ihrem Mann und dem Sohn.

Wie in den obigen Ausschnitten bereits anklang, zeigte sich bezüglich der Komponente Assertivität, die die Dimension Durchsetzungsorientierung prägt, dass S11 und ihr Mann, nachdem sie einmal auf die Gefahr eines Übertritts in die nicht erwünschte Abteilung B aufmerksam gemacht worden waren, stetig und mit Festigkeit (vgl. insb. die Episode M115) ihre wert- und kontrollbezogenen Einschätzungen vertreten hatten: «logisch bleibt man dran» (M105).

Bezüglich der Komponente emotionale Zuwendung, bei der zwischen den einzelnen Elternteilen dieser Gruppe die größten Unterschiede bestanden (vgl. Tabelle 7.16), wies S11 die am häufigsten auftretende Ausprägung eher hoch (3) auf: Bei einem Erfolg in einer Mathematikprüfung freute sie sich intensiv mit K11: «Dann sind wir alle happy (lacht), super, und cool und schön und so» (vgl. Anhang, Tabelle 9.5). Bei einem Misserfolg diskutierte und analysierte sie mit ihrem Sohn die Fehler wohlwollend:

«'Oh, Scheiße, oh nein' und so, und dann wird es aber durchgeschaut, also wird die Prüfung durchgeschaut, wo denn - ja, was er nicht verstanden hat oder warum - einfach irgendwie auch für ihn zum Merken: 'He, das sind ja Flüchtigkeitsfehler' oder: 'He, 
da hast du die Frage falsch verstanden' oder; 'He, da hast du's falsch ausgerechnet', also zum Wissen, wo der Fehler liegt, also sie wird durchgeschaut» (vgl. Anhang, Tabelle 9.5).

Unmittelbar enttäuscht, analysierte sie zusammen mit ihrem Sohn die Prüfung, indem sie offenbar versuchte, sowohl den Fehlern sachlich auf den Grund zu gehen, als auch selber selbstwertdienliche Ursachen (Flüchtigkeit, Zeitdruck) anzuführen.

Dieser Ausschnitt vermag die Ausgewogenheit gut zu erfassen, die im verbalen Motivierungshandeln der Elternteile des Typs 4 über weite Strecken zu Tage trat: Einerseits versuchte die Mutter hier den schulischen Anforderungen Genüge zu tun, indem sie mit ihrem Sohn die Fehler analysierte («falsch verstanden», «falsch ausgerechnet», «wo der Fehler liegt») und so zu seinem Kompetenzerwerb beitrug, andererseits wurde sie dem Bedarf ihres Sohnes nach Selbstwertschutz gerecht, indem sie auch selber gesichtswahrende Ursachen wie «Flüchtigkeit» bzw. «Zeitdruck» nannte. Aus höherer Warte betrachtet, zeigt sich die Ausgewogenheit dieses Motivierungstyps auch darin, dass die Eltern dieser Gruppe als einzige aus der Stichprobe auf allen drei grundlegenden Dimensionen bei der jeweils zentralsten Facette Gemeinsamkeiten aufwiesen - und dabei bemerkenswerterweise jene Ausprägungen aufwiesen, die - wie in den vergangenen Abschnitten bereits mehrmals dargelegt - als motivationsförderlich bezeichnet werden können:

So behielten diese Eltern während der unsicheren Übertrittszeit

a) die schulischen Normen (Anforderungen, Standards und Erwartungen) im Blick, indem sie ihr Kind durch die Betonung diesbezüglich positiver Aspekte (belohnendes Ziel, das dadurch erreicht werden kann) dafür zu gewinnen suchten (Normorientierung),

b) gleichzeitig waren sie darum bemüht, die Perspektive des Kindes einzunehmen und ihre wert- und kontrollbezogenen Botschaften auf die in einem stark dialogischen Vorgehen gewonnenen Informationen über die Sichtweisen des Kindes anzupassen (Kindorientierung), und

c) ebenso verloren sie ihr eigenes Bedürfnis nicht aus den Augen, sich in ihrer Rolle als Eltern als selbstwirksam zu erleben und vom Kind als Autorität als valide Normsetzer, als Beurteiler, als erfahrene Welterklärer und Berater etc. - anerkannt zu werden, indem sie mit eher hoher Assertivität auf eine Internalisierung ihrer Botschaften hinarbeiteten und dem Kind diesbezügliche Herausforderungen zumuteten. 
Auch wenn die große Mehrheit der Elternteile dieser Gruppe vorwiegend die autonomiegefährdenden Wesentlichkeitsargumente einsetzte und noch stärker kindbezogene, internale Aspekte zur Plausibilisierung von Bedeutsamkeiten hätten verwenden können (vgl. Abschnitt 8.4), so erscheint dieser Motivierungstyp, der mit der Ausnahme von S11 nur von Eltern praktiziert wurde, die selber die Abteilung B der Sekundarschule besucht hatten (vgl. Tabelle 7.20), dabei aber durchgängig hohe (2) bis sehr hohe (3) Aspirationen für einen Übertritt ihres Kindes in die Abteilung A bekundeten (vgl. Tabelle 3.2), mit Blick auf die Motivationsförderung als der Kompletteste, der in der Stichprobe auftrat.

\subsection{Schlussfolgerungen für die Forschung}

Bevor im abschließenden Abschnitt 8.4 der pädagogischen Frage nach dem idealen verbalen Handeln von Eltern und anderen Erziehenden zur schulbezogenen Motivationsförderung nachgegangen wird, werden im Folgenden die methodischen Überlegungen, auf denen das Forschungsdesign dieser Studie beruhte, einer kritischen Beurteilung unterzogen und Folgerungen für zukünftige empirische Studien gezogen.

\subsubsection{Mit leitfadengestützten Interviews verbale Handlungen von Eltern erfassen}

Das Hauptziel dieser Studie bestand darin, eine Exploration in die verbalen motivationsbezogenen Unterstützungsprozesse im Elternhaus im Kontext eines unklaren Übertrittsentscheids zu unternehmen und das konkrete verbale Handeln der Eltern, über das bis anhin kaum Näheres bekannt war, hinsichtlich seiner motivationsförderlichen Gestaltung möglichst detailliert zu beschreiben und die dafür notwendigen Begriffe und Instrumente zu entwickeln.

Sprachliche Handlungen werden im Hinblick auf die Auswertung grundsätzlich am besten audiovisuell erfasst. Nach den ersten Versuchen, die Familien mit Videokameras oder Audioaufnahmegeräten auszustatten und sie elterliche Unterstützungen bei Hausaufgaben filmen zu lassen, wurde aus mehreren Gründen wieder davon Abstand genommen: Einerseits entfaltet sich der elterliche Einfluss auf die schulbezogene Motivation bei weitem nicht nur in eigentlichen Lehr-LernSituationen, sondern in vielen weiteren häuslichen Situationen, in denen Schule inzidentell zum Gesprächsinhalt wird und die Eltern ihre Wertüberzeugungen 
und Aspirationen, evaluativen Feedbacks und Erwartungen zum Ausdruck bringen (vgl. Abschnitt 2.2.2). Andererseits hatten die Gespräche mit den Kindern und Eltern, die anhand einer Anleitung selbständig probehalber diesbezügliche Videoaufnahmen angefertigt hatten, ergeben, dass sie sich an ihrem heimischen Esstisch in einer künstlichen Laborsituation gewähnt hatten und dass sie sich bei Hausaufgaben, die das Kind normalerweise alleine erledigte, zur Zusammenarbeit gezwungen sahen. Ebenso bleib bei einer Fokussierung auf Lehr-Lern-Situationen unklar, wie dem Einfluss des uneindeutigen Übertritts, der ein zentrales Forschungsinteresse der TRANSITION-Studie darstellte (vgl. Kapitel 3), Rechnung getragen werden sollte. Die genannten Schwierigkeiten führten dazu, dass die Lösung in leitfadengestützten Interviews gesucht wurde. Interviews sind ein etabliertes Mittel zur Erhebung von subjektiven Beobachtungen, Einschätzungen und Überzeugungen und ermöglichen es Forschenden, auch in Realitätsbereiche wie das Familienleben vorzustoßen, in die sie nur begrenzten Zugang haben (vgl. Misoch, 2015, S. 256). Allerdings eröffneten sich hierbei neue Schwierigkeiten, die namentlich die Validität der Selbstbeschreibungen eigenen Handelns betreffen:

So war erstens mit selbstwertdienlichen und sozial erwünschten Schilderungen der Eltern zu rechnen, was die Beschreibung ihres eigenen sozialen Handelns in der zugespitzten Situation des unsicheren Übertritts betraf. Dem Problem wurde insbesondere dadurch begegnet, dass mit den Kindern die unmittelbaren Interaktionspartner mit parallelen Fragen zu ihrer Wahrnehmung der betreffenden Unterstützungsaspekte und jeweils typischer Kommunikationssituationen befragt wurden. Auch wenn die Kinderinterviews erwartungsgemäß generell kürzer und weniger detailliert ausfielen, und z. T. beträchtliche Unterschiede zu den Schilderungen der Erwachsenen aufwiesen, so herrscht nach Abschluss einer Reihe von Studien im qualitativen Projektteil des Forschungsprojekts dennoch der Eindruck vor, dass das Vorgehen namentlich bei den Eltern viel dazu beigetragen hat, dass sie sich sachgemäßer, selbstkritischer und erklärender über ihr Handeln geäußert hatten. Die Maßnahme paralleler Interviews zur Erhöhung der Akkuratheit von Schilderungen eigener Handlungen ist unbedingt zu empfehlen.

Zweitens mussten die Fragen nach der Anzahl Interviews und damit verbunden nach der Situationsspezifität der Handlungsschilderungen gelöst werden. Führt man lediglich wenige Interviews durch - im vorliegenden Fall beispielsweise ein prospektiv ausgerichtetes zu Beginn und ein retrospektiv ausgerichtetes am Ende der Übertrittszeit -, so erfassen diese gezwungenermaßen vor allem generalisierte Aspekte des eigenen sozialen Handelns («normalerweise mache ich das so...»). Dabei besteht die Gefahr, dass situationsspezifisches oder untypisches, aber dennoch manchmal auftretendes Handeln, welches u. U. einen besonders starken und 
bleibenden Effekt auf die Interaktionspartner hat, aus dem Blickfeld der Befragten gerät. Mit dieser Überlegung und ebenso vor dem Hintergrund, dass es sich beim Übertritt um ein Verfahren handelte, das sich zeitlich erstreckte und unterschiedliche Ereignisse beinhaltete (vgl. Abbildung 6.1), wurde in der vorliegenden Studie das Vorgehen gewählt, dass möglichst unmittelbar nach übertrittsrelevanten Ereignissen (vgl. Abschnitt 6.1) kürzere telefonische handlungsnahe Interviews mit den Elternteilen und den Kindern geführt wurden. Lediglich zu Beginn und am Schluss fanden längere, die Wahrnehmung des eigenen Handelns auf einer generalisierteren Ebene erfassende Gespräche statt. Es gibt im Rückblick zahlreiche Hinweise dafür, dass das zweite dieser face-to-face-Interviews, welches die Datengrundlage für die vorliegende Studie bildete, hinsichtlich der Validität der Selbstberichte über das eigene Handeln durch das beschriebene Vorgehen deutlich profitiert hat: So ist es zum Beispiel fraglich, ob der Vater Z22 in diesem Interview so freimütig von seinem «Auftischen» von Forderungen an seine Tochter berichtet hätte (vgl. Abschnitt 8.2.3), wenn er und sie davor nicht anlässlich eines situationsspezifischen Interviews im Rahmen einer Prüfungsbesprechung seine drastischen Reaktionen nach einer ungenügenden Note seiner Tochter geschildert hätten (vgl. Ulmann, 2012). Stehen die entsprechenden ökonomischen Mittel zur Verfügung, ist ein Kombinieren von Interviews, die Schilderungen eigenen Handelns auf einer generalisierten, bilanzierenden Ebene erheben, mit solchen, die situationsspezifisch und sehr handlungsnah geführt werden, zur Erhöhung des Realitätsbezugs unbedingt zu empfehlen.

Drittens musste mit Blick darauf, dass in der vorliegenden Studie bestimmte Aspekte des Sprechhandelns im Zentrum stehen sollten, der Gestaltung des Leitfadens und der Durchführung der Interviews besondere Aufmerksamkeit geschenkt werden. Einerseits sollten die im Leitfaden formulierten Fragen dem für die qualitative Forschung grundlegenden methodologischen Prinzip der Offenheit (vgl. Helfferich, 2005, S. 100-103; Lamnek \& Krell, 2016, S. 33-34) genügen und nicht zu direkt und zu eng gefasst - also abfragend und bestimmte Antworten nahelegend (vgl. Gläser \& Laudel, 2010, S. 135) - das interessierende motivationsbezogene sprachliche Handeln erheben, andererseits sollte dieses von den Proband*innen möglichst zahlreich, detailliert und episodisch erzählt werden. Nach entsprechenden Erprobungen wurden die in Tabelle 6.1 aufgeführten Fragen den 20 Elternteilen möglichst gemäß der Reihenfolge ihrer Auflistung und gemäß ihrer Gewichtung (Einleitungsfragen vs. Sondierungsfragen, vgl. Abschnitt 6.3.1) gestellt. Generell wurde die Reihenfolge der Fragen in den einzelnen Themenblöcken so gewählt, dass einleitend die Überzeugungen und Einschätzungen der Eltern zum entsprechenden Aspekt erfragt wurden und im Anschluss Fragen zur 
diesbezüglichen Kommunikation mit dem Kind - oft im Sinne von Sondierungsfragen - folgten. Mit diesem eher vorsichtigen Vorgehen war die Erwartung (und Hoffnung) verbunden, dass die Eltern möglichst von sich aus bereits im ersten Teil des jeweiligen Themenblocks auf ihre diesbezüglichen wert- und kontrollbezogenen Appelle gegenüber dem Kind zu sprechen kämen und dass die Interviewenden die diesbezüglich expliziteren Sondierungsfragen bei Bedarf eher akzentuierend einzusetzen könnten. Zwar hat sich gezeigt, dass sich in den Interviews letztlich insgesamt eine ansehnliche Zahl entsprechender Handlungsschilderungen fand, doch muss im Rückblick konstatiert werden, dass die inhaltsanalytische Auswertung - namentlich die Basiscodierung, vgl. unten - zeitlich ökonomischer hätte gestaltet werden können, wenn direkter und bereits in der Einleitung zum entsprechenden Themenblock nach dem entsprechenden Handeln gefragt worden wäre. So haben sich jene Fragestrategien und Aufforderungen, die in den oben erwähnten situationsspezifischen Interviews angesichts der besonderen Umstände - ca. 15 Minuten Zeit, telefonisch geführt und unmittelbar an ein Ereignis anknüpfend - unumgänglich waren, im Rückblick ebenfalls in den umfangreichen face-toface-Interviews als besonders ergiebig zur Erfassung generalisierterer sprachlicher Handlungsformen erwiesen: z. B. «Was haben Sie mit Ihrem Kind diesbezüglich konkret besprochen?», «Wie reagierten Sie, als Ihr Kind...?», «Wie läuft das bei Ihnen $a b$, wenn...?», «Können Sie mir schildern, was ich hätte beobachten können, wenn ich dabei gewesen wäre?».

Bezüglich der Durchführung der Interviews hat sich sodann gezeigt, dass genügend Zeit in die Ausbildung, aber ebenso in das fortlaufende Coaching der Interviewenden während der Erhebungsphase investiert werden muss. Rückblickend lässt sich feststellen, dass es wichtig ist, dass in Studien mit einer vergleichsweise hohen Zahl an Proband*innen und einem längsschnittlichen Design wie der vorliegenden, die Befragenden in den periodisch stattfindenden Projektsitzungen nicht nur über Inhalte und Probleme der vorangegangenen und der nächstfolgenden Interviewwelle beraten, sondern sich auch immer wieder vergewissern, ob ihr Frageverhalten den Vorgaben entspricht und sich über die Zeit kongruent entwickelt ${ }^{3}$. Wie sich gezeigt hat, variierte die Länge der in der vorliegenden Studie untersuchten Interviews nicht nur zwischen den Proband*innen, sondern auch zwischen den Befragenden, die jeweils zwei Eltern-Kind-Dyaden betreut hatten, zum Teil beträchtlich. Gerade weil den Befragenden Spielraum zugestanden wurde, in welchem Maß sie die Sondierungsfragen einsetzen und wie

\footnotetext{
${ }^{3}$ Für weitergehende Überlegungen zur Qualitätssicherung in qualitativ ausgerichteten Projekten in großen Forschungsgruppen, vgl. Vasarik Staub, Galle, Stebler und Reusser (2019).
} 
stark sie bei einsilbigeren Interviewpartner*innen mit Nachfragen Präzisierungen zum konkreten Handeln elizitieren wollten, konnten letztlich die Erzählungen von zwei Elternteilen in den höher-inferenten Analysen wegen einer insgesamt zu geringen Episodenzahl nicht berücksichtigt werden (vgl. Abschnitt 6.4.1.3.).

Zusammengefasst ist demnach zu empfehlen, die Frageformen zur Erhebung des generalisierten (verbalen) Handelns in Interviews sprachlich an solchen zu orientieren, die zur Erfassung situationsspezifischen Handelns notwendig sind. Sodann sollte in längsschnittlichen Interviewstudien in großen Forschungsgruppen grundsätzlich darauf geachtet werden, dass unter den Interviewenden ein stetiges Vergleichen des eigenen Frageverhaltens stattfindet und sich die Techniken laufend erweitern, mit denen sie ihre Interviewpartner*innen in Nachfragen um Präzisierungen ihrer Handlungsschilderungen bitten.

\subsubsection{Mit verschiedenen deskriptiven Methoden Selbstberichte eigenen verbalen Handelns auswerten}

Die vorliegende Studie besaß ein aufwändiges, mehrschrittiges und multimethodisches Auswertungssetting, das sich an der «Typologischen Analyse» von Kuckartz (2010, S. 99-107) orientierte. Im Folgenden werden zentrale Aspekte und Probleme der vier Analyseschritte kritisch erörtert und daraus methodenbezogene Empfehlungen für die weitere empirische Forschung sowie Ideen für Anschlussstudien entwickelt.

\subsubsection{Analyseschritt A: Basiscodierung}

Im ersten Analyseschritt wurden die Transkripte der Interviews einer Basiscodierung unterzogen, in der alle Schilderungen eigener schulbezogener Regulationshandlungen der Eltern bezüglich der Werteinschätzungen, der Kontrolleinschätzungen, der in schulischen Situationen erlebten Emotionen und des Lernverhaltens der Kinder in einem vorwiegend induktiven Vorgehen erfasst wurden (vgl. Abschnitt 6.4.1). Bezugnehmend zur Diskussion im vorangehenden Kapitel zur Form, wie in Interviews das Handeln der Akteure erfragt werden soll, zeigte sich nun, dass ein direkteres Erfragen die Entwicklung eines Codiersystems und der nachfolgenden Analyse insofern beträchtlich erleichtert hätte, als bestimmte Fragen mit ihren jeweiligen Antworten zu Analyseeinheiten hätten bestimmt werden können. Im vorliegenden Fall dienten die ganzen, sehr umfangreichen Interviews als Basis für die Entwicklung eines Codiersystems und es musste über die Fragen hinweg nach den Stellen gesucht werden, in denen sich die interessierenden 
Konstrukte finden ließen. Damit die strukturierende Inhaltsanalyse mit akzeptablen Intercoder-Übereinstimmungen durchgeführt werden konnte, musste allein zur Festlegung der Grenzen der zu extrahierenden Stellen in einem zeitaufwändigen iterativen Prozess eine verhältnismäßig große Zahl an Codierregeln festgelegt werden (vgl. Steiner et al., 2010). Das gewählte Verfahren ermöglichte zwar erst die nachfolgenden detailreichen niedrig-inferenten Analysen zu den Gestaltungsmerkmalen der solchermaßen extrahierten Wert- und Kontrollepisoden im Analyseschritt B. Es hätte sich jedoch hier bei begrenzteren personalen, zeitlichen und monetären Ressourcen die Möglichkeit geboten - allerdings mit den erwähnten Abstrichen bei den Fragestellungen 1 und 2 (vgl. Abschnitt 5.8) -, eine Abkürzung des Analyseprozesses vorzunehmen und direkt mit den höherinferenten Ratings der evaluativen qualitativen Inhaltsanalyse des Analyseschrittes C einzusetzen, indem nur die Antworten der Eltern auf bestimmte handlungsbezogene Fragen einer Einschätzung unterzogen worden wären. Dies lässt sich am Beispiel des Ratings zur Bestimmung des Grades an emotionaler Zuwendung (vgl. Abschnitt 6.4.3.4) illustrieren, für das lediglich die Antworten auf die letzten beiden Hauptfragen des Blocks B des Leitfadens (vgl. Tabelle 6.1) herangezogen wurden, in denen die Eltern um eine Beschreibung davon gebeten wurden, wie es bei ihnen zuhause ablaufe, wenn das Kind eine gute oder eine ungenügende Note nach Hause bringe (vgl. Abschnitt 6.4.1.1).

\subsubsection{Analyseschritt B: Schaffung von Frames und von Kategoriensystemen zur Analyse der Wert- und Kontrollregulationen}

Hätte die Extrahierung von Handlungsepisoden aus ökonomischen Gründen nicht in der aufwändigen komplexen Form durchgeführt werden können wie sie im vorliegenden Projekt in der Basiscodierung erfolgt ist, so wären zwei innovative Aspekte, die im Zuge des Analyseschrittes B Gestalt annahmen, nicht möglich gewesen: Zum einen hat sich nach der Basiscodierung gezeigt, dass die extrahierten Fundstellen (erwartungsgemäß) in unterschiedlicher Detailliertheit das kommunikative Geschehen zwischen Eltern und Kindern schilderten. Während die Elternteile ihre Appelle und die Reaktionen der Kinder in einzelnen Stellen mittels direkter Reden «nachspielten», äußerten sie in anderen primär ihre eigenen wertund kontrollbezogenen Überzeugungen und zeigten lediglich mit wenigen Worten an (mittels der verba dicendi und Wendungen, die das Mitteilen signalisieren wie z. B.: «man muss ihn manchmal dazu ermuntern», vgl. Abschnitt 6.4.1.2), dass sie diese dem Kind weitergegeben hätten. Um die Vergleichbarkeit herzustellen, musste das Prinzip der Frames entwickelt werden (vgl. Abschnitt 6.4.2). Die Frames boten den Codierenden eine heuristische Struktur an, entlang derer sie sich 
die elterlichen Situationsschilderungen vergegenwärtigen, möglichst textsensitiv nach den interessierenden Aspekten absuchen sowie schließlich unter bestmöglicher Wahrung des propositionalen Gehaltes reformulieren konnten. Die hohen Ad-hoc-Interrater-Übereinstimmungen der strukturierenden qualitativen Inhaltsanalysen (vgl. Tabelle 6.2), die letztlich an den solchermaßen standardisierten reformulierten Aussagen durchgeführt wurden, zeigen, wie unmittelbar einleuchtend und hilfreich das Verfahren war, das die aus motivationstheoretischer Sicht interessierenden Aspekte besonders scharf hervortreten ließ und eine gemeinsame Diskussionsbasis bot, falls sich die beiden getrennt voneinander Codierenden in einem ersten Durchgang nicht einig waren.

Die zweite Innovation, die in diesem Untersuchungsschritt erzielt wurde, besteht im Kategoriensystem «Elterliche Strategien der verbalen Wertvermittlung» (vgl. Abbildung 5.4), welches die Analyse der motivationsrelevanten Argumentationen erlaubt, die die Eltern gegenüber dem Kind zur Veranschaulichung der Bedeutung einsetzten, die sie bestimmten schulischen Zielen zumaßen. Während im Rahmen der Forschung um Reattributionen und attributionsbasierte Interventionsstrategien (zsf. Perry \& Hamm, 2017; Schunk et al., 2014, S. 115-119) auf der Basis von Weiners dreidimensionalem Klassifikationsschema (1994, S. 271) (vgl. Tabelle 5.1) seit langem ähnliche Instrumente für die Analyse von attributionalen Begründungen existieren, welche Erziehende in Kontrollregulationen gegenüber Kindern einsetzen (vgl. Abschnitt 5.3.3.2) - zur Schaffung des diesbezüglichen Kategoriensystems (vgl. Abbildung 5.3) war in der vorliegenden Studie entsprechend eine verhältnismäßig geringe Eigenleistung notwendig (vgl. Abschnitt 5.4.1) -, existierte mit Wissen des Autors bis anhin nichts Vergleichbares für die Analyse von Wertregulationen. Auf der Basis der Theorie um subjective task values (vgl. Eccles, 2005; Wigfield \& Eccles, 1992) und den extrahierten Wertepisoden geschaffen, stellt das Kategoriensystem ein wichtiges Ergebnis der Studie dar, das ohne die oben beschriebene aufwändige Extraktion solcher Interviewstellen im Rahmen der Basiscodierung kaum möglich gewesen wäre. Das an motivationstheoretischen Konstrukten und an Interviewdaten entwickelte Analysesystem, das eine umfassende Begrifflichkeit zum Verständnis solcher Regulationen zur Verfügung stellt, muss in einem nächsten Schritt in weiteren Studien um die value intervention von Eltern und anderen Erziehenden validiert werden. Dabei stellt sich insbesondere die Frage, wie verschiedene Strategien der Wertvermittlung (vgl. Abbildung 5.3) auf Schülerinnen und Schüler mit unterschiedlichen Wert- und Kontrollüberzeugungen wirken. Entsprechende experimentelle Studien - fast immer im Kontext von Unterrichtssituationen durchgeführt (vgl. Abschnitt 5.6.2) - sind wie erwähnt noch immer sehr rar und 
sollten in Anbetracht der Alltäglichkeit und der mutmaßlichen Bedeutung solcher verbalen Regulationen unbedingt zahlreicher aufgelegt werden.

\subsubsection{Analyseschritte $C$ und D: Ratings zur Bestimmung des individuellen Motivierungsstils und Schaffung einer Taxonomie}

Mit Bezug zu den Befunden der höher inferenten Ratings, welche jeweils bei allen individuellen Wert-, Kontroll- und Prüfungsbesprechungsepisoden der 18 Elternteile hinsichtlich der sieben Qualitätsdimensionen des verbalen Motivierens durchgeführt worden sind (vgl. Abschnitt 6.4.3), stellen sich namentlich die beiden folgenden Fragen:

a) Inwiefern vermochten die ermittelten Stile bzw. die im Analyseschritt D generierten Typen des verbal-appellativen Motivierungshandelns die tatsächlichen Praktiken der Elternteile während der Übertrittszeit darzustellen?

b) Inwiefern haben diese nicht nur situationsbedingt in der vorliegenden Stichprobe Gültigkeit, sondern lassen sich verallgemeinern und übertragen (vgl. Flick, 2019, S. 274-278)?

Beide Fragen betreffen letztlich die externale Validität, die sich in qualitativen Projekten mit den typisch geringen Fallzahlen normalerweise nicht wie in der quantitativen Forschung über die Zufalls- oder Quotenauswahl eines umfangreichen Samples sowie statistischer Inferenzschlüsse sicherstellen lässt, sondern wie Kuckartz (2018) meint, über eine «sorgfältige Fallauswahl»- diesbezüglich sei auf Abschnitt 6.2 verwiesen - sowie «Strategien [...], die allgemein geeignet sind, die Verallgemeinerbarkeit von empirischen Befunden zu erhöhen» (S. 218).

Zur Beantwortung der Frage a) nach der Realitätsnähe der erzielten Befunde besteht eine solche Strategie in der Gegenvalidierung der aus den generalisierten Interviews erzielten fallspezifischen Ergebnisse an denjenigen, die sich in anderen Studien desselben Forschungsprojekts ergeben haben: Dank des längsschnittlichen Settings des qualitativ ausgerichteten Teils der TRANSITION-Studie (vgl. Abbildung 6.1) und den Teilstudien, die in den letzten Jahren auf der Grundlage der situativen Interviews mit den Elternteilen, den Kindern sowie deren Klassenlehrkräfte fertiggestellt wurden (vgl. Curschellas Widmer, 2015; Dellios, 2013; Good, 2014; Haymoz, 2014; Ulmann, 2012; Zaugg, 2014), lässt sich die Gegenvalidierung insofern bewerkstelligen, als sich in ihnen weitere Selbstund Fremdberichte zum verbalen Handeln der untersuchten 18 Elternteile finden lassen. Während die anekdotische Evidenz für eine große Übereinstimmung zwischen den diesbezüglichen Befunden der verschiedenen Analysen spricht, steht eine empirisch-systematische Überprüfung dieser Hypothese noch aus. Sie ließe sich ferner mit der Strategie des member checking koppeln (vgl. Kuckartz, 2018, 
S. 218): Dabei werden die Eltern und ihre mittlerweile erwachsenen Kinder, die nun einen beträchtlichen zeitlichen Abstand zur damaligen aufwühlenden Übertrittssituation besitzen und die ihr (gegenseitiges) Handeln vermutlich nicht nur milder, sondern auch selbstkritischer zu sehen vermögen, mit den sie betreffenden Befunden konfrontiert und um eine Stellungnahme und Perspektivierung gebeten. Mit Blick auf die motivations- und emotionstheoretischen Konstrukte von besonderem Interesse wäre dabei die Perspektive der 18 damaligen Kinder. Die Interviews, die mit ihnen als 12-Jährige gemacht wurden, waren gerade hinsichtlich der in der vorliegenden Studie zentralen motivational-affektiven Konstrukte wenig ergiebig gewesen (vgl. Curschellas Widmer, 2015). Dieser Umstand machte es notwendig, dass die vorliegende Studie, welche diesbezügliche Interventionen der Eltern in den Blick nahm, sich auf primär deskriptive Aspekte beschränken musste und sich das elterliche Handeln nicht direkt an motivationsbezogenen Äußerungen der Kinder spiegeln ließ. Die Berichte über ihr damaliges Erleben der elterlichen Appelle und die Auswirkungen, welche sie den verbalen Wertund Kontrollregulationen der Eltern für ihr lern- und leistungsbezogenes Handeln sowie für ihre weitere Schul- und Berufskarriere zumessen, wären dabei von primärem Interesse. Die Durchführung einer solchen Anschlussstudie wird vom Autor in Betracht gezogen.

Ferner besteht die Möglichkeit, die Ergebnisse - und dies betrifft nun auch die Frage b) nach deren Generalisierbarkeit - mittels integrativen Ansätzen der sog. Methodentriangulation (vgl. Denzin, 1978; Kelle, 2008) nicht nur hinsichtlich deren Konvergenz, sondern auch hinsichtlich deren Komplementarität (vgl. Kuckartz, 2014, S. 58) an den Befunden und Einschätzungen der Eltern und Kinder aus dem quantitativ ausgerichteten Projektteil der TRANSITION-Studie zu spiegeln und zu perspektivieren.

\subsection{Schlussfolgerungen und Empfehlungen für die pädagogische Praxis}

Die Bedeutung der vorliegenden Studie für die pädagogische Praxis besteht vor allem darin, dass sie eine Reihe von Begriffen, Konzepten und Qualitätskriterien hervorgebracht hat, die Eltern und weiteren Erziehenden als Instrumentarium zur Reflexion und Regulation ihrer schulbezogenen Kommunikation gegenüber ihrem Kind an die Hand gegeben werden kann.

Wie sich in früheren Weiterbildungsveranstaltungen mit Eltern gezeigt hat, lassen sie sich nach einer Einführung in die Grundlagen der Motivationstheorie, in der sie vor allem mit der Bedeutung von Wert- und Kontrollkognitionen für das 
Lern- und Leistungshandeln ihrer Kinder bekannt gemacht werden (vgl. Kapitel 5), mit Interesse auf den nächsten Schritt ein, in welchem sie ihr Augenmerk ihrem eigenen verbalen Handeln widmen. Sie werden dabei mit dem Gedanken vertraut gemacht, dass sie als Eltern mit ihren alltäglichen schulbezogenen Erwartungsäußerungen, ihren Leistungsbewertungen, Aufforderungen, Wünschen, Korrekturen etc. letztlich immer auch die beiden genannten motivationsrelevanten Überzeugungssysteme beim Kind aktivieren und dass sie folglich mit ihren entsprechenden Äußerungen dessen situative Kontroll- und Werteinschätzungen so zu beeinflussen vermögen, dass sich beispielsweise Angstzustände verringern (z. B. «Schau, du hast perfekt auf die morgige Prüfung gelernt, indem du ... - Aber selbst, wenn du mal eine schlechtere Note nach Hause bringen solltest, bricht für uns Eltern deshalb doch keine Welt zusammen.») oder vergrößern (z. B. «Es ist dir hoffentlich klar, dass du morgen unbedingt reüssieren musst!»).

Bei einer entsprechenden vertieften Beschäftigung mit den in der vorliegenden Studie erarbeiten Kategorien, so wird an den genannten Beispielen klar, dürfte sich der Blick von Eltern auf die eigenen an das Kind gerichteten Appelle dahingehend schärfen lassen, damit es ihnen möglich wird, ihre Appelle - orientiert an ihren Zielen und am wahrgenommenen Bedarf des Kindes - gezielt sprachlich so zu formen, dass sich die Wahrscheinlichkeit erhöht, die erwünschten Veränderungen in der Wert- und Kontrolleinschätzung des Kindes zu bewirken. Damit Eltern dies gelingt, dürfte es ausreichen, wenn sie sich mit den Einschätzungskategorien vertraut machen, die im Rahmen der höher-inferenten Analyseschritte auf der Grundlage der erwartungs-werttheoretischen Konstrukte und den Interviewdaten entwickelt worden sind (vgl. Abschnitt 6.4.3).

Bevor sie sich mit den gestalterischen Aspekten ihrer schulbezogenen Wertund Kontrollregulationen beschäftigen, dürfte es allerdings sinnvoll sein, dass sich die Eltern der eigenen motivationalen Orientierungen und Überzeugungen bewusst werden, denen ihr Regulationshandeln unterliegt (vgl. Abschnitt 4.1.2). Wie die Ergebnisse der Hauptkomponentenanalyse belegen, richtet sich der Blick von Eltern in zugespitzten schulischen Leistungssituationen mindestens in drei Richtungen, die in der vorliegenden Studie als «grundlegende Orientierungen» bezeichnet worden sind (vgl. Abschnitt 7.4.1). In einer ersten metakognitiven Annäherung an ihr Motivierungshandeln wäre es demnach angezeigt, dass sich die Eltern mit der Frage beschäftigen, wie sie sich persönlich auf den folgenden drei Dimensionen positionieren - sei es vor dem Hintergrund des Übertritts oder sei es allgemein mit Blick auf Anforderungen, welche die Schule an das Kind und an sie heranträgt: 
A) Normorientierung: Bei dieser Dimension geht es um den Positionsbezug der Eltern gegenüber den von ihnen wahrgenommenen Normen, Standards und Erwartungen der Schule und ihrer Akteure und darum, welche Bedeutung sie diesen beimessen. Ihre diesbezüglichen Erfahrungen und Überzeugungen, so hat sich in der Studie gezeigt, sind insbesondere mit der Art assoziiert, wie sie dem Kind gegenüber die Bedeutsamkeit der schulischen Ziele vermitteln und wie emotional zugewandt sie darauf reagieren, wenn das Kind die entsprechenden Anforderungen nicht erfüllt (vgl. Tabelle 7.15).

Folgende Fragen dürften Eltern zur Analyse und Reflexion der eigenen Normorientierung behilflich sein:

Wie wichtig ist es Ihnen, dass Ihr Kind mit Blick auf sein Lernen und Leisten, auf sein Arbeitsverhalten und auf sein sozial-kommunikatives Verhalten dem Bild einer konformen Schülerin bzw. eines konformen Schülers entspricht? Welche Anforderungen stellt der Übertritt an Ihr Kind? Inwiefern sind Ihnen einzelne der genannten Anforderungen an das Kind wichtiger als andere? Wie würden Sie mit anderen Worten die Rolle einer Schülerin bzw. eines Schülers definieren und bezüglich welcher Aspekte gibt es Ihrer Ansicht nach Handlungs- und Entscheidungsspielraum für das Kind und für Sie als Eltern selber?

B) Kindorientierung: Bei dieser Dimension geht es um den Positionsbezug der Eltern gegenüber den von ihnen wahrgenommenen sozialen, emotionalen und kognitiven Bedürfnissen des Kindes und darum, welche Bedeutung sie diesen beimessen. Ihre diesbezüglichen Überzeugungen, Haltungen und Einschätzungen sind insbesondere damit assoziiert, wie dialogisch sie mit ihrem Kind kommunizieren und an dessen Sichtweise interessiert sind, in welchem Maß sie in Situationen, in denen sie gegenüber dem Kind Leistungsbewertungen vornehmen, dessen Bedürfnis nach Selbstwertschutz berücksichtigen und in welchem Maß sie ihr Kind mit Argumenten zu überzeugen suchen, die seine Interessen ins Zentrum stellen (vgl. Tabelle 7.15).

Zur Eruierung der eigenen Kindorientierung dürften den Eltern die folgenden Fragen hilfreich sein:

Was wissen Sie darüber, was Ihrem Kind an Schule und Unterricht a) Spaß macht, b) besonders wichtig ist, c) Mühe bereitet, d) Bauchschmerzen bereitet? Wie gehen Sie vor, wenn Sie dies erfahren möchten? Wie gehen Sie vor, wenn Sie mit dem Lernen und den Leistungen Ihres Kindes zufrieden sind? Wie gehen Sie vor, wenn Sie mit dem Lernen und den Leistungen Ihres Kindes nicht zufrieden sind? Worauf muss man bei Ihrem Kind achten, wenn man mit ihm über seine Fehler und seine Unzulänglichkeiten beim Lernen sprechen möchte? Inwiefern stellen Sie dem Kind den Nutzen, den Sie in einer schulischen Vorgabe oder Anforderung erkennen, aus seiner Perspektive dar? 
C) Durchsetzungsorientierung: Bei dieser Dimension geht es um den Positionsbezug der Eltern gegenüber ihren eigenen Bedürfnissen, sich bei ihrer schulbezogenen Unterstützung als selbstwirksam und als vom Kind anerkannt zu erleben: Sei es, indem es ihren Appellen Beachtung schenkt, indem es die wert- und kontrollbezogenen Botschaften beherzigt sowie indem es diese zunehmend mit seinem veränderten Handeln erkennen lässt. Die diesbezüglichen Einschätzungen, Überzeugungen und Haltungen der Eltern sind insbesondere damit assoziiert, wie prägnant sie bei ihren wert- und kontrollbezogenen Appellen vorgehen, wie klar sie für ihre eigenen diesbezüglichen Positionen bei Widerspruch oder Nichtbeachtung durch das Kind einstehen und mit welcher Verbindlichkeit und Ausdauer sie auf einer diesbezüglichen Verhaltensregulation durch das Kind bestehen (vgl. Tabelle 7.15).

Zur Analyse und Reflexion der eigenen Durchsetzungsorientierung dürften die folgenden Fragen hilfreich sein:

Worin sehen Sie Ihre Aufgaben, wenn es um die Unterstützung Ihres Kindes geht? Wie wichtig ist es Ihnen, Ihr Kind von ihren schulbezogenen Einschätzungen und Sichtweisen zu überzeugen? Wie schaffen Sie es, die Aufmerksamkeit Ihres Kindes für Ihre Erwartungsäußerungen und Wünsche zu erhalten? Inwiefern schaffen Sie es, dass sich Ihr Kind Ihre diesbezüglichen Botschaften zu Herzen nimmt? In welchen Bereichen schaffen Sie das eher schlecht? Was unternehmen Sie dann?

Auf der zweiten Ebene des Instrumentariums zur Reflexion und Regulation des eigenen verbalen Motivierungshandelns - derjenigen der Stilkomponenten - finden sich die sieben Merkmale, mit denen in der Studie der individuelle Stil der Proband*innen analysiert wurde (vgl. Abschnitt 6.4.3). Sich einmal der eigenen Orientierungen beim schulbezogenen verbalen Motivieren bewusst, ermöglichen es die sieben Komponenten, bestimmten Aspekten desselben besondere Aufmerksamkeit zu schenken, sich diesbezüglich kritisch zu hinterfragen und allenfalls Intentionen und Strategien zur Verbesserung des eigenen Stils zu entwickeln. Die sieben Komponenten können mit anderen Worten der Evaluation, dem Monitoring und der Planung von Optimierungen dienen, womit ihnen die Rolle eigentlicher «Stellschrauben» zukommt. Zum Abschluss dieser Skizze einer Intervention, die sich an interessierte Eltern richtet, werden mit Blick auf die Komponenten Empfehlungen formuliert. Dazu werden die Konstrukte jeweils bezüglich ihrer förderlichen Form nochmals kurz inhaltlich bestimmt und hinsichtlich ihrer Funktionalität im Regulationsprozess erläutert. 
Betonung von Zweckmäßigkeit bei Wertregulationen

Es ist Eltern grundsätzlich zu empfehlen, dass sie bei ihren Wertregulationen darauf achten, dem Kind die Zweckmäßigkeit eines bestimmten schulbezogenen Handelns für ein vom Kind selber als erstrebenswert anerkanntes «größeres» Ziel klarzumachen: «Es ist bedeutsam, dass du das machst, weil du so dein Ziel erreichst». Anders als Wesentlichkeitsargumente, die von den meisten der untersuchten Eltern gemäß ihren Erzählungen am häufigsten eingesetzt wurden («Es ist bedeutsam, dass du das machst, weil du das in deiner Rolle als Schüler*in einfach musst»), führen Bedeutsamkeitsregulationen mit Zweckmäßigkeitsargumenten dem Kind nicht den Zwang vor Augen, der sich aus dem Hinweis auf Rollen und Pflichten ergibt, sondern gewähren ihm zumindest die Wahl zwischen dem gewohnten und dem vom Elternteil empfohlenen alternativen Handeln. Betonen Eltern die Zweckmäßigkeit, nehmen sie somit eine beratende Funktion ein, formulieren Empfehlungen und signalisieren dem Kind, ohne die Verantwortung zu vernachlässigen, ihm Guidance zu geben (vgl. Skinner, E. A. et al., 2009, S. 65), dass sie ihm zutrauen, solche Entscheidungen selber zu treffen (vgl. Abschnitt 5.6.2.3). Eltern wirken somit autonomieförderlich - eine Handlungsqualität, die sich gemäß der Selbstbestimmungstheorie (vgl. Ryan \& Deci, 2016) und einer konsistenten diesbezüglichen Befundlage positiv auf die Internalisierung solcher external-fremdregulierter Verhaltensformen auswirkt und diese zu internal-selbstregulierten bzw. - in der Terminologie von Eccles (2005) - zu attainment values werden lässt (vgl. Abschnitte 5.5.1.2 und 5.5.1.3).

Betonung positiver Aspekte bei Wertregulationen

Eltern ist es sodann zu empfehlen, ihre Kinder mit positiv-valenten Argumenten von der Bedeutsamkeit eines Handlungs- oder Leistungsziels zu überzeugen. Im Zuge der oben empfohlenen Zweckmäßigkeitsargumente betonen sie somit die belohnenden Konsequenzen und versuchen im Sinne der Lerngesetze des operanten Konditionierens (vgl. Skinner, B. F., 1971, 1989), das Kind für das erwünschte Handeln zu gewinnen. Setzen sie negativ-valente Argumente ein, wie dies die Eltern des Motivierungstyps 1 typischerweise taten (vgl. Abschnitt 8.2.1), so heben sie die Kosten eines anderen als von ihnen empfohlenen Handelns hervor, formulieren also ein Gebot («Es ist bedeutsam, dass du das machst, weil du sonst...») und schränken die von der Argumentationsstrategie der Zweckmäßigkeit signalisierte Entscheidungsfreiheit umgehend wieder ein (vgl. Abschnitt 5.6.2.1).

Betonung internaler Aspekte bei Wertregulationen

Bezüglich der Frage, ob Eltern eher internale oder eher externale Aspekte in ihren Wertregulationen einsetzen sollen, fällt die Antwort weniger eindeutig aus. Bei 
den oben empfohlenen positiven Zweckmäßigkeitsargumenten bezeichnen internale Argumente appetitive Konsequenzen unmittelbar für das Kind selbst (z. B. «weil du dich dann besser fühlst» oder «weil du die Sache dann besser verstehst»). Externale positive Zweckmäßigkeitsargumente weisen dahingegen auf appetitive Konsequenzen im Bereich von Zielen hin, die Instanzen außerhalb des Kindes gesetzt haben und allgemein als erstrebenswert gehalten werden: «weil du dann den Übertritt in die Abteilung A schaffst». Wie die beiden unterschiedlichen Referenzbereiche auf die Motivation wirken, dürfte von den motivationalen Tendenzen des jeweiligen Kindes abhängen. Kinder, die eine mastery goal orientation (vgl. Dweck, 1986; Nicholls, 1984) zeigen und mit einer individuellen Bezugsnorm vornehmlich darauf bedacht sind, ihre Kompetenzen zu entwickeln und die Lerngegenstände gründlich zu verstehen (vgl. Abschnitt 4.2.1.2), dürften sich vermutlich von internalen Gründen stärker angesprochen fühlen. Umkehrt kann vermutet werden, dass Kinder, die eine performance goal orientation aufweisen und - an einer sozialen Bezugsnorm orientiert - primär darauf ausgerichtet sind, sich vor andern als kompetent und leistungsfähig zu erweisen (bzw. ihre scheinbaren Defizite nicht sichtbar zu machen), stärker auf externale Argumente in der elterlichen Begründung aufmerksam werden (vgl. Abschnitt 5.6.2.2).

\section{Zugeschriebene Kontrolle}

Es ist Eltern grundsätzlich zu empfehlen, dass sie in ihren evaluativen Feedbacks darauf achten, einen adaptiven Pfad einzuschlagen (vgl. Perry \& Hamm, 2017, S. 71) und bei Handlungsaspekten des Kindes, zu denen sie ein negativvalentes Urteil abgeben möchten («Merke dir: Du hast es schlecht im Griff») auf kontrollierbare, variable Faktoren - fehlende Anstrengung, schlechte Strategien oder geringe Aufmerksamkeit - zu attribuieren, was beim Kind Zuversicht erzeugt («ich kann es in den Griff kriegen»). Dies wiederum führt zu günstigeren motivationalen Zuständen, welche die Wahrscheinlichkeit eines Erfolgs erhöhen. Möchten sie ein positiv-valentes Urteil abgeben («Merke dir: Du hast es gut im Griff»), sollte die Argumentation sowohl aus fähigkeits- als auch aus anstrengungsbezogener Information bestehen. Die Sequenzierung der beiden Ursachenzuschreibungen dürfte dabei zentral sein. Bei einer intermittierenden Darbietung, also der zufälligen Fremdzuschreibung mal der einen, mal der anderen Ursache, ergeben sich keine vorteilhafteren Effekte als bei der ausschließlichen Darbietung von lediglich einem der beiden Faktoren (vgl. Dresel, 2004, S. 202). So dürfte es ratsam sein, eine Feedbackstrategie zu wählen, bei der positiv-valente Urteile zeitlich separiert zu Beginn der Beschäftigung mit einem neuen Lernbereich erst mit Anstrengung und mit fortschreitendem Wissenserwerb schließlich mit Fähigkeit erklärt werden (vgl. Dresel \& Ziegler, 2006). 
Diskursivität bei Wert- und Kontrollregulationen

Es hat sich im Verlauf der Studie als zentral erwiesen, dass Eltern bei ihren verbalen Regulationen diskursiv-dialogisch vorgehen und sich ein möglichst adäquates Bild der schulbezogenen Sichtweisen, Vorlieben, Ängste und Wünsche des Kindes machen. So deuten die Ergebnisse der experimentellen Studien von Canning und Harackiewicz (2015) zu value interventions darauf hin, dass die oben für die Internalisierung und Interessenerzeugung als förderlich dargestellten ZweckmäBigkeitsargumente ihre produktive Wirkung nur dann entfalten, wenn das Kind a) dem von den Eltern präsentierten Zweck selbst tatsächlich eine hohe Bedeutung beimisst, b) die Zweckmäßigkeitsaussage für glaubwürdig hält und c) über möglichst positive Kontrollüberzeugungen bezüglich der angesprochenen Aktivität sowie bezüglich des genannten Zwecks verfügt (vgl. Abschnitt 5.6.2.3). Ebenso wirken positive Argumente lediglich dann als positive Verstärker, wenn das Kind diese auch wirklich als belohnend empfindet. Alle diese Bedingungen lassen sich von den Eltern umso besser erfüllen, je stärker sie mit ihm im Dialog sind, wenn sie selber ihre Zweckmäßigkeitsargumente erklären, das Kind Stellung nehmen lassen und wenn sie ihm entsprechend adaptiertere und plausiblere Erklärungen und Beispiele anzubieten haben und sich dann zurückzunehmen wissen, wenn es sein Verstehen oder ein genügendes $\mathrm{Ma} ß$ an Internalisierung erkennen lässt. Gerade in schwierigen Situationen mit Hausaufgaben, in Situationen, in denen das Kind Misserfolge zu verkraften hat oder in solchen, in denen die Eltern die unrealistisch hohen Erfolgserwartungen des Kindes zu dämpfen versuchen wenn dem Kind also unter Berücksichtigung seiner psychologischen Bedürfnisse ein realitätsnahes, seine Leistungen benennendes Feedback gegeben werden soll, - dürfte ein hoher Grad an Dialogizität auch in Kontrollregulationen notwendig sein (vgl. Abschnitt 5.7).

Assertivität bei Wert- und Kontrollregulationen

Eltern ist unbedingt zu empfehlen, in ihren Wert- und Kontrollregulationen verbindlich aufzutreten und dem Kind gegenüber zwar ruhig, aber deutlich zum Ausdruck zu bringen, dass es ihnen wichtig ist, es von der Angemessenheit ihrer Sichtweise zu überzeugen. Eltern dürften nämlich vor allem dann, die für die Internalisierung und Befolgung der Wert- und Kontrollregulationen notwendige Aufmerksamkeit wecken und hinreichend überzeugend wirken, wenn sie einen angemessenen Grad an Assertivität aufweisen (vgl. Aebli, 1997, S. 273-275). Es gilt, das Kind aktiv anzusprechen, wenn einen etwas stört, erklärend Stellung zu beziehen und bei seinem Widerspruch oder seiner Weigerung, sein Verhalten anzupassen, nicht gleich klein beizugeben. Bei einer solchermaßen zum Ausdruck gebrachten Verbindlichkeit geben sich die Eltern als Expertinnen und Experten für 
den schulischen Realitätsbereich zu erkennen (vgl. Sofsky \& Paris, 1991, S. 27), denen es wichtig ist, das Kind zu seinem Wohl aus der Perspektive der Erfahreneren zu beraten. Es zeigt sich aber auch hierbei die Bedeutung der Diskursivität: Damit die Strukturgebung, die die Eltern mit ihrem Insistieren auf ihren Überzeugungen sicherstellen, in den Augen des Kindes nicht als Zwang (coersion) (vgl. Tabelle 2.1) erscheint, dürfte es wichtig sein, dass die Eltern bei ihren Kontrollund Wertregulationen nicht monologisch vorgehen, Widerspruch und Rückfragen des Kindes aufnehmen und auf stures Beharren verzichten (vgl. Abschnitt 5.7).

\section{Emotionale Zuwendung}

Eltern sollten sodann stets bedenken, dass eine Internalisierung der wert- und kontrollbezogenen Botschaften, die einem «inner indorsement» (Grolnick, 2003, S. 56) gleichkommt - also mehr ist als einfach eine vordergründige Beachtung und Befolgung derselben solange die Eltern anwesend sind -, nicht zu erreichen ist, wenn sie einen Kommunikationsstil pflegen, der zwar von hoher Diskursivität und hoher Assertivität geprägt ist, dem Kind aber gerade im Zuge von evaluativen Feedbacks und von Prüfungsbesprechungen die Möglichkeit verwehrt, sein Gesicht zu wahren und Vertrauen und Zuversicht zu fassen: «Children will be most likely to internalize regulations when relatedness needs are met, meaning when they have a positive relationship with an involved, supportive parent» (Grolnick, 2003, S. 56).

Erleben sich Kinder in einem liebevollen Elternhaus (warmth, vgl. Tabelle 2.1), in dem man sich trotz seines gelegentlichen Widerspruchs und Nachfragens und trotz seiner augenscheinlich geringen Einsicht grundsätzlich wohlwollend mit allen Facetten seiner Persönlichkeit auseinandersetzt, dann bringen sie den Mut auf, zu ihren Handlungen zu stehen und ihre Meinungen und Emotionen frei zu äußern. Ebenso wird ihnen so möglich, sich auf die elterlichen Argumente zu konzentrieren, indem sie sich nicht ständig mit dem Selbstwertschutz und mit Gedanken zur Beziehungsqualität auseinandersetzen müssen (vgl. Wood et al., 1976, S. 98). Nehmen Eltern also Abstand von Missachtungen, von feindseligen und erniedrigenden Äußerungen und entschuldigen sie sich bei ihm, wenn sie in Konfliktsituationen zu solchen Formen der rejection gegriffen haben (vgl. Skinner, E. A. et al., 2009, S. 186), so schaffen sie eine Beziehungsqualität, welche die Internalisierung elterlicher schulbezogener Werte und Erwartungen fördert (u. a. Grolnick \& Ryan, 1989; Grolnick et al., 1991; Simpkins et al., 2006; zsf. Wigfield, Eccles, et al., 2015, S. 25).

Appelle, so lässt sich mit Grusec (2011) abschließend zusammenfassen, wirken umso nachhaltiger und überzeugender, je bestimmter und standfester die Eltern ihre Positionen vertreten (Assertivität), je verständnisförderlicher sie dabei 
vorgehen (Diskursivität) und je stärker sie in eine vertrauensvoll-fürsorgliche Beziehung eingebettet sind (Emotionale Zuwendung):

Thus, reasoning, a warm and affectionate parent-child relationship, and power assertion work together: Reasoning provides an understanding of rules and standards that promote their internalization, modest amounts of power assertion provide the motivation that focuses children's attention and encourages them to listen and to engage in the learning process, and warmth promotes acceptance of the parental message. (Grusec, 2011, S. 257)

Open Access Dieses Kapitel wird unter der Creative Commons Namensnennung 4.0 International Lizenz (http://creativecommons.org/licenses/by/4.0/deed.de) veröffentlicht, welche die Nutzung, Vervielfältigung, Bearbeitung, Verbreitung und Wiedergabe in jeglichem Medium und Format erlaubt, sofern Sie den/die ursprünglichen Autor(en) und die Quelle ordnungsgemäß nennen, einen Link zur Creative Commons Lizenz beifügen und angeben, ob Änderungen vorgenommen wurden.

Die in diesem Kapitel enthaltenen Bilder und sonstiges Drittmaterial unterliegen ebenfalls der genannten Creative Commons Lizenz, sofern sich aus der Abbildungslegende nichts anderes ergibt. Sofern das betreffende Material nicht unter der genannten Creative Commons Lizenz steht und die betreffende Handlung nicht nach gesetzlichen Vorschriften erlaubt ist, ist für die oben aufgeführten Weiterverwendungen des Materials die Einwilligung des jeweiligen Rechteinhabers einzuholen.

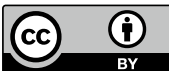

